Article

\title{
Experimental Data for the Validation of Numerical Methods: DrivAer Model
}

\author{
Max Varney ${ }^{1}$, Martin Passmore ${ }^{1, *}$, Felix Wittmeier ${ }^{2}$ and Timo Kuthada ${ }^{2}$ (D) \\ 1 Aeronautical and Automotive Engineering, Loughborough University, Loughborough LE11 3TU, UK; \\ M.Varney@lboro.ac.uk \\ 2 Forschungsinstitut für Kraftfahrwesen und Fahrzeugmotoren Stuttgart (FKFS), 70569 Stuttgart, Germany; \\ Felix.Wittmeier@fkfs.de (F.W.); timo.kuthada@fkfs.de (T.K.) \\ * Correspondence: M.A.Passmore@lboro.ac.uk
}

Received: 30 October 2020; Accepted: 30 November 2020; Published: 8 December 2020

check for updates

\begin{abstract}
As the automotive industry strives to increase the amount of digital engineering in the product development process, cut costs and improve time to market, the need for high quality validation data has become a pressing requirement. While there is a substantial body of experimental work published in the literature, it is rarely accompanied by access to the data and a sufficient description of the test conditions for a high quality validation study. This paper addresses this by reporting on a comprehensive series of measurements for a $25 \%$ scale model of the DrivAer automotive test case. The paper reports on the measurement of the forces and moments, pressures and off body PIV measurements for three rear end body configurations, and summarises and compares the results. A detailed description of the test conditions and wind tunnel set up are included along with access to the full data set.
\end{abstract}

Dataset: https://repository.lboro.ac.uk/articles/dataset/DrivAer_Experimental_Aerodynamic_ Dataset/12881213

Dataset License: CC BY-NC 4.0

Keywords: automotive aerodynamics; aerodynamic dataset; drivAer model; drivAer dataset; experimental dataset

\section{Introduction}

The use of virtual methods in the Automotive sector to design, develop and validate vehicles has increased rapidly over the past two decades. This has been particularly important in vehicle aerodynamics where the use of Computational Fluid Dynamics (CFD) has almost completely replaced experimental approaches in the early design phases for manufacturers. The ability to make good decisions, based on the CFD output, depends on the aerodynamicist's understanding of the strengths and weakness of the method and having confidence in the overall accuracy of the output. An important element in providing this confidence is the validation of the numerical methods using high quality, well defined experimental data.

An example of a relatively comprehensive multi-purpose experimental dataset is the SAE 20 degree notchback model data from Wood et al. [1]. At the time of writing the dataset had been downloaded over 1400 times, demonstrating the urgent need for such data, and a number of authors [2-5] have reported using it for validating CFD methodology. The Wood et al. [1] dataset was collated from data generated by three researchers, in three different studies, over a number of years rather than being purpose designed for publication as a dataset from the outset. This resulted in some limitations in the 
data, arising for example, from differences between experiments in the Particle Image velocimetry (PIV) processing approaches or model set up; but, the success of the data set illuminates the need for much more experimental validation data.

In response to this demand, this paper reports on a new purpose built dataset [6] using three configurations of a 25\% scale DrivAer model. Since its creation in $2012[7,8]$, the DrivAer model has become a popular test case for studies where a realistic vehicle is preferred to a simplified geometry, as commonly used for studies of the underlying aerodynamic fundamentals. The DrivAer has therefore found applications in CFD [9-37] particularly for the validation of commercial code, and increasingly by Original Equipment Manufacturers (OEM's) for more generic experimental work [7,8,32-46]. However, because the model has a large number of variations, with three main rear end geometries, three cooling flow options, three under-body, two tyre and two wheel configurations, it is difficult to find two studies that use the same geometry. This difficulty is compounded when also considering different wind tunnel configurations, including fixed or moving ground simulation, working section design and the model scale. This problem is illustrated in Table A1 which collates experimental results for the DrivAer model from seven different publications, covering over 100 configurations, but does not show a single comprehensive resource that can be accessed in detail for any new investigation.

This paper addresses these shortcomings by presenting a dataset [6] designed to provide a cohesive and comprehensive set of results acquired in a single tunnel in a single experimental campaign. The processing applied to the data is explained in full and shortcomings in the set up, testing methodology and test to test variability are included. Forces and moments, pressures and off body PIV measurements are included, and the paper summarises and compares the results for the three configurations. To maximise the ability to make direct comparisons with CFD the Loughborough University Large Wind Tunnel geometry and inlet conditions are provided as are the accurate locations of instruments providing the reference measurements. The dataset [6] includes the instantaneous and time averaged data for all configurations and tests, to allow individuals or organisations to trial different processing methods on a unified set of data.

\section{Experimental Methodology}

\subsection{Facilities}

All tests were performed in the Loughborough University Large Wind Tunnel, shown in Figure 1, an open return tunnel with a $2.5 \mathrm{~m}^{2}$ rectangular closed working section and a static ground plane. The working section is $3.6 \mathrm{~m}$ long with cross section dimensions of $1.92 \mathrm{~m} \times 1.3 \mathrm{~m}$ with $0.2 \mathrm{~m}$ chamfers in each of the corners. The flow quality in the tunnel is $\approx 0.2 \%$ onset freestream turbulence with a flow uniformity of $0.4 \%$ [47]. The inlet boundary layer profile can also be found in Johl [47].

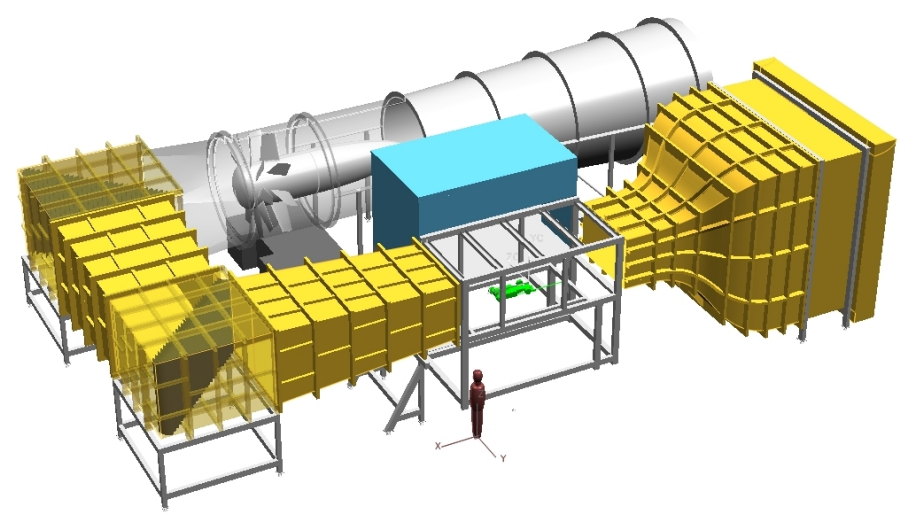

Figure 1. Loughborough University Large Wind Tunnel [47]. 
In order to improve the ability to correlate fully between the CFD and the experimental work, the full CAD geometry of the wind tunnel contraction and working section is included in the downloadable dataset.

\subsection{Model}

The model used is a variant of the DrivAer model built by FKFS Stuttgart. The base model is the standard model downloaded from the Technical University of Munich website [48], but in this configuration it includes a porous radiator, detailed engine bay and cooling flow, a detailed underbody and 5 spoke wheels with tyre tread and wing mirrors. The model has been tested in all three rear-end configurations, the estateback (squareback or station wagon), fastback and notchback (saloon).

A significant deviation from the downloadable geometry is the mounting of the wheels; in this instance, the wheels are mounted to the model with components simulating a MacPherson strut for the front wheels (Figure 2a) and a rigid axle for the rear wheels (Figure 2b). Images showing these components in more detail, with associated dimensions are supplied in the dataset [6].

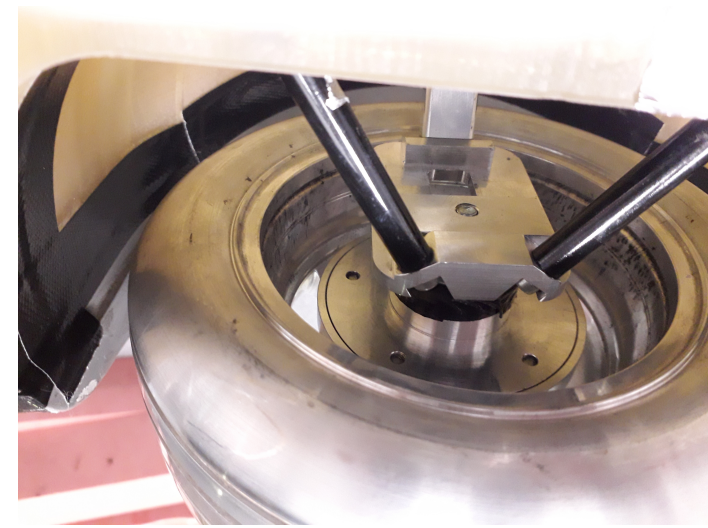

(a)

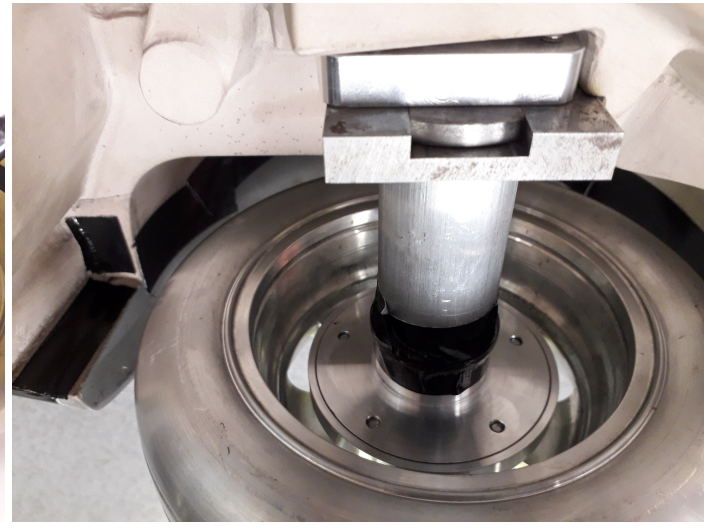

(b)

Figure 2. Images of the components used to mount the wheels to the model, at the front (a) and, rear (b).

The model ride height in the wind tunnel was set to match that in the downloadable CAD geometry [48]. This results in a distance between the floor and the top of the wheel arches of $0.172 \mathrm{~m} \pm 0.0005 \mathrm{~m}$ and $0.171 \mathrm{~m} \pm 0.0005 \mathrm{~m}$ for the front and rear arches respectively. The model was maintained at this ride height throughout the testing using steel mounting pins protruding through the floor. These can be seen in the image of the installation in Figure 3. The pins are attached to the live side of the underfloor balance allowing force and moment measurements to be taken. The pin positions and geometry are included in the dataset [6].

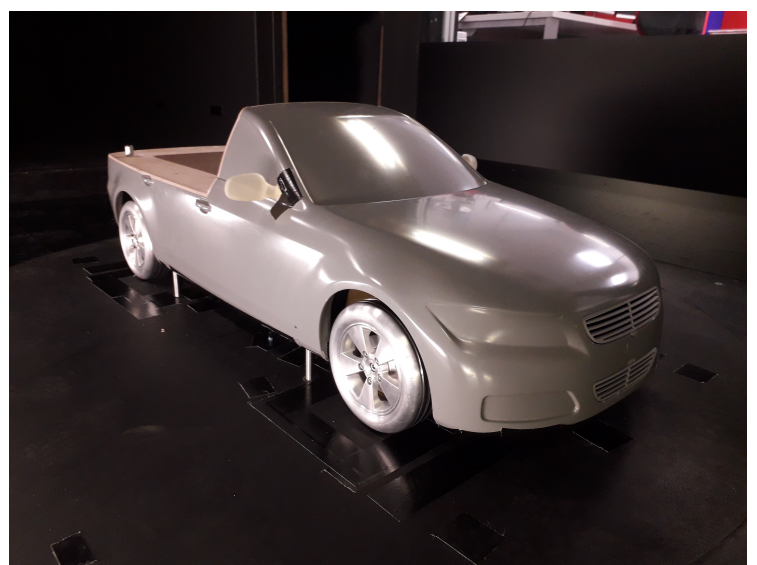

Figure 3. The DrivAer model installed in the Loughborough University Large Wind Tunnel without a rear geometry. 
The wheels on this model were designed to be rotated when installed with a moving ground plane, so in the fixed floor configuration of the Loughborough University Large Wind Tunnel the wheels were prevented from rotating by fixing them to the suspension. All 4 wheels were fixed into the same orientation seen in Figure 3, this matches the orientation when importing the CAD geometry.

With the model body at the correct ride height the bottom of the wheels were adjusted to give $0.004 \mathrm{~m}$ clearance around the wheel in a matched machined section in the floor, as illustrated in Figure 4. The floor geometry is also included in the dataset [6].

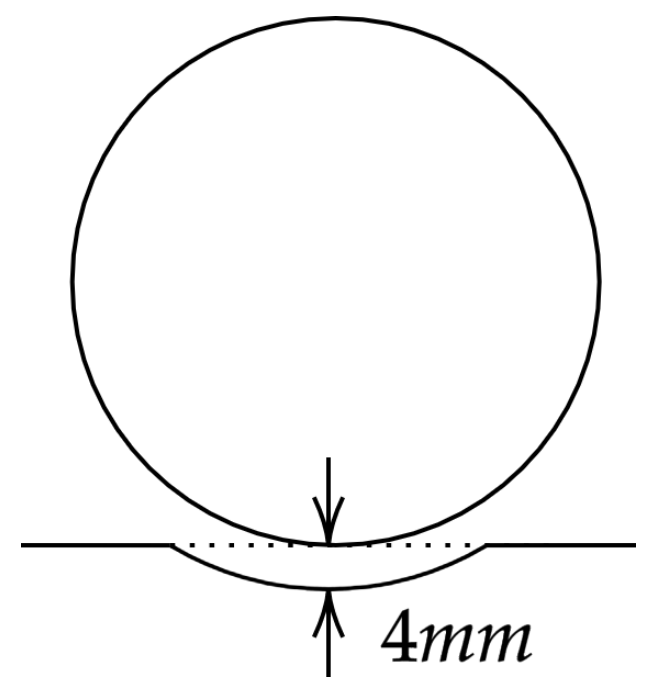

Figure 4. Illustration of the machined wheel pads preventing contact between the live model and grounded tunnel.

The pressure drop representing the radiator is achieved in the model using an hexagonal expanded aluminium honeycomb and a square perforated sheet. The honeycomb was a $0.003 \mathrm{~m}$ hexagon structure with a $0.00006 \mathrm{~m}$ wall thickness, measuring $0.010 \mathrm{~m}$ deep. The square perforated sheet uses $0.008 \mathrm{~m}$ holes with $0.004 \mathrm{~m}$ spacing between the holes and a depth of $0.0006 \mathrm{~m}$. In addition to this $25 \%$ of the holes were covered to generate a greater pressure drop. Images of the honeycomb and the perforated plate are included in the downloadable dataset [6].

As simple automotive geometries often exhibit long time wake dynamics, that can be very sensitive to yaw, it is now common to define the $0^{\circ}$ yaw condition for a model as the condition where it generates a symmetric base pressure distribution $[49,50]$. As this model is not symmetric, due to the underbody and engine bay flow, this approach could not be used. Instead the model was yawed until it was geometrically aligned between the tunnel walls and the edge of the model pins, this was estimated to be within $\pm 0.0005 \mathrm{~m}$, equating to $0^{\circ} \pm 0.2^{\circ}$ yaw. Using this measurement the model was also found to be laterally centred in the tunnel to within $0.002 \mathrm{~m}$. As the yaw position was fixed during testing, the annular gap between the rotating disc attached to the balance and the rest of the tunnel floor was sealed to prevent any flow bleeding into the tunnel whilst logging data.

\subsection{Measurements}

The data presented in the paper and the dataset [6] have not been corrected for blockage and the flow field measurements are not normalised in the dataset. For presentation purposes in this paper it is necessary to normalise, so where this is done the method used is indicated. The approach, of providing raw data in the dataset, is adopted because the inclusion of the tunnel geometry and inlet conditions in the dataset makes it possible to replicate the experimental conditions exactly in any simulation. A direct comparison between CFD and the experimental data is then possible, with any normalising of the data handled by the user to suit the analysis and presentation. This approach allows for better transparency and improved understanding of the correlation. 
Figure 5, illustrates the model sensitivity to Reynolds number (Equation (1)). For all rear end configurations the drag coefficient reduces by approximately 0.008 between a length based Reynolds number of approximate $2.5 \times 10^{6}$ and $3.5 \times 10^{6}$, showing that the model is not completely Reynolds insensitive. This is typical for models that include small scale details, such as those included in the cooling path and underbody for these cases. At the highest Reynolds number tested (a tunnel speed of $45 \mathrm{~m} / \mathrm{s}$ ) some instantaneous drag data fell outside the maximum operating range of the balance so all subsequent measurements were taken at the wind tunnels nominal operating speed of $40 \mathrm{~m} / \mathrm{s}$, with the specific data provided in each individual test case. $40 \mathrm{~m} / \mathrm{s}$ gives a length based Reynolds number of $2.94 \times 10^{6}$.

$$
\operatorname{Re}=\frac{\rho \cdot v_{\infty} \cdot L}{\mu}
$$

where $\rho$ is the air density $\left(\mathrm{kg} / \mathrm{m}^{3}\right), L$ is the characteristic length presented here as the model length (m) and $\mu$ is the dynamic viscosity of air $(\mathrm{Pa} \cdot \mathrm{s}) . v_{\infty}$ is the freestream velocity $(\mathrm{m} / \mathrm{s})$ as measured at the pitot-static tube $X=1.70 \pm 0.02 \mathrm{~m}$ upstream, $Y=0.500 \pm 0.005 \mathrm{~m}$ and $Z=1.180 \pm 0.005 \mathrm{~m}$ from the tunnel origin.

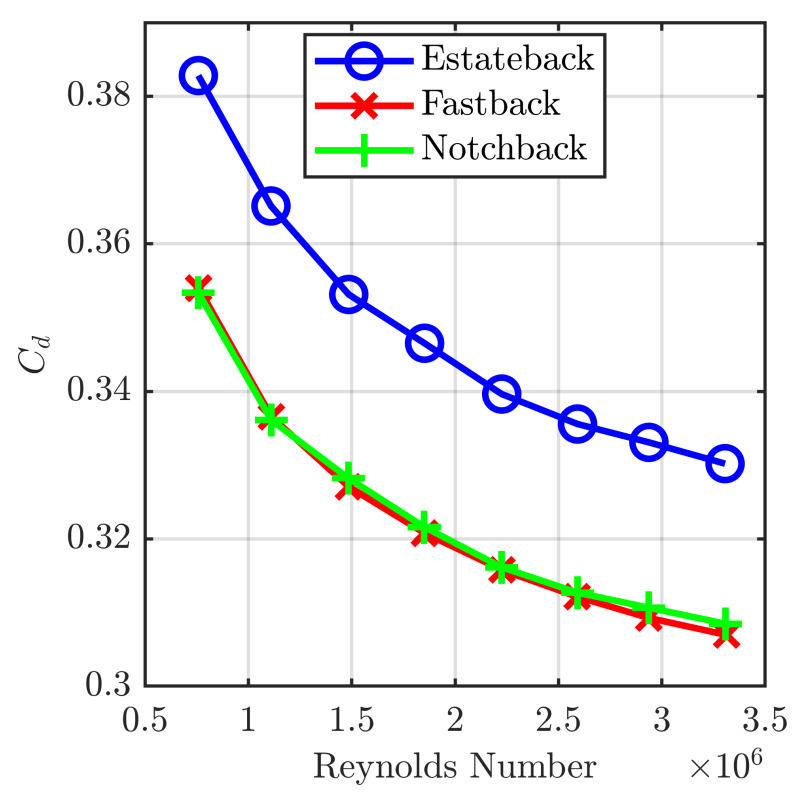

Figure 5. Reynolds sweep for the drag coefficient for each DrivAer geometry.

To increase the range of possible applications of the data, surface pressure and force and moment data was acquired during the collection of every PIV plane. This makes it possible to assess variability in the experimental data and make comparisons with CFD in ways that are not normally possible. Note however, that the data is not time synchronised so it is not possible to cross-correlate directly between forces, pressures and PIV. The PIV measurement planes at the rear of the model are sampled for $300 \mathrm{~s}$, and the plane in the front stagnation region is sampled for $100 \mathrm{~s}$.

A wind-off force and pressure tare was performed prior to spooling the tunnel up for each configuration.

\subsubsection{Force}

Force measurements were carried out using an under-floor 6 axis virtual centre balance, with the origin located on the floor of the working section in the centre of the turntable. The model is positioned centrally on the turntable so that the origin is mid-track, mid-wheelbase on the ground plane, and all forces and moments presented use the sign convention set out in SAE J1594 [51]. 
Data was sampled at $300 \mathrm{~Hz}$, with no filter, with an arithmetic mean of the data taken in post processing. The calculations for the force and moment coefficients are presented in Equations (2) and (3) respectively with the front and rear lift $\left(C_{l f}\right.$ and $\left.C_{l r}\right)$ calculations presented in Equation (4).

$$
C_{f}=\frac{F}{\frac{1}{2} \rho \cdot A \cdot v_{\infty}^{2}}
$$

where $C_{f}$ represents the force coefficient and $A$ is the projected frontal area of the model $\left(\mathrm{m}^{2}, 0.136 \mathrm{~m}^{2}\right.$ for all tested configurations).

$$
C_{m}=\frac{M}{\frac{1}{2} \rho \cdot L_{m} \cdot A \cdot v_{\infty}^{2}}
$$

where $L_{m}$ is the wheelbase of the model ( $m, 0.697 \mathrm{~m}$ for all configurations tested).

$$
\begin{aligned}
& C_{l f}=\frac{1}{2} C_{l}+C_{m y} \\
& C_{l r}=\frac{1}{2} C_{l}-C_{m y}
\end{aligned}
$$

where $C_{l f}$ and $C_{l r}$ are the front and rear lift coefficients, $C_{l}$ is the total lift coefficient and $C_{m y}$ is the pitching moment coefficient.

\subsubsection{Pressures}

The surface pressure tapping locations are distributed over the interchangeable upper-rear geometry as illustrated in Figure 6. In total there are 60 measurement locations on the notchback and 62 measurement locations on the estateback and fastback.
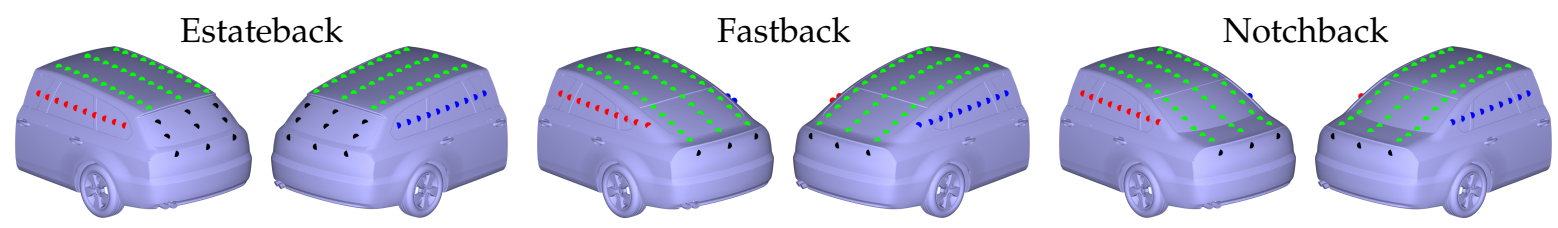

Figure 6. Pressure tapping locations and groupings on the DrivAer geometries.

Pressures were measured using a single 64 channel differential pressure scanner sampling at $260 \mathrm{~Hz}$ per channel. The pressure scanner has a range of $\pm 0.232 \mathrm{mH}_{2} \mathrm{O}$ and an accuracy of $\pm 0.1 \%$ of the full scale measurement. The pressures are referenced to an upstream static on a pitot-static tube located $X=1.69 \pm 0.02 \mathrm{~m}$ upstream, $Y=0.650 \pm 0.005 \mathrm{~m}$ and $Z=1.158 \pm 0.005 \mathrm{~m}$ from the model origin. The total pressure from the same device is also connected to one of the 64 channels to facilitate the calculation of the pressure coefficients using Equation (5). As the pressure scanner is a multiplexed device running at $\approx 20,000 \mathrm{~Hz}$ the measurements from individual pressure tappings are not time aligned. However in post processing the data is re-sampled to time-align it, see Wood [52], making it possible to apply spatial cross-correlations or similar methods.

$$
C_{p}=\frac{p-p_{s}}{\frac{1}{2} \rho \cdot v_{\infty}^{2}}=\frac{p-p_{s}}{p_{t}-p_{s}}
$$

where $C_{p}$ is the pressure coefficient, $p$ is the pressure measured at the model surface, $p_{s}$ represents the static pressure measured at the upstream pitot and $p_{t}$ represents the total pressure measured at the upstream pitot.

The pressure tappings consist of $\approx 0.001 \mathrm{~m}$ bore brass tubes connected to the scanner with $\approx 0.5 \mathrm{~m}$ long smooth bore silicone tubing. The tubing lengths are approximately consistent and no transfer function correction has been applied. 
As the scanner is located inside the model the connecting cables and silicone tubes for the upstream pitot-static were routed out of the model in the wake of the front wheel and front mounting pins to minimise the impact of the cabling on the flow. This can be seen in Figure 7.

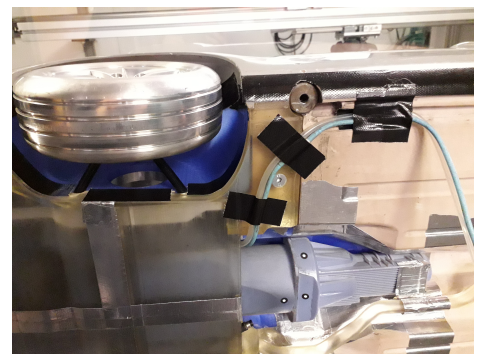

(a)

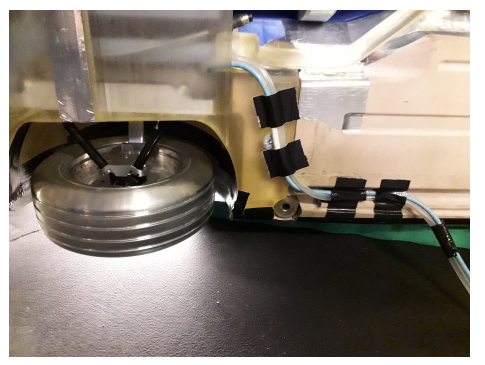

(b)

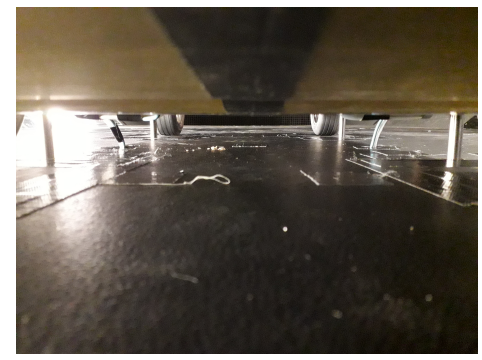

(c)

Figure 7. Images showing the pressure scanner cable routing. (a) Routing on the left hand side $(-Y)$ of the model; (b) Routing on the right hand side $(+Y)$ of the model; (c) Routing from both sides down and through the floor.

\subsubsection{Velocity Field}

All velocity field measurements were made using planar two component Particle Image Velocimetry (PIV) using commercially available hardware and software from LaVision ${ }^{\circledR}$. While more comprehensive measurements using our usual approach of volumetric tomographic PIV, complemented by highly spatial resolved planar three component was desirable, the much simpler planar two component implementation has been used here because the model surface finish generated reflections that precluded other approaches. However, by employing two cameras it was possible to capture a large field of view, with all of the equipment outside of the flow field. For measurement planes in the wake the data has been sampled at $5 \mathrm{~Hz}$, for $300 \mathrm{~s}$ giving 1500 image pairs, and $100 \mathrm{~s}$ in the stagnation region giving 500 image pairs.

The flow is seeded with $1 \mu \mathrm{m}$ Di-Ethyl-Hexyl-Sebacate particles, continuously introduced in the contraction of the tunnel, to seed the bulk flow, and additionally at the start of the working section (Figure 8), to seed the boundary layer and underbody flow.

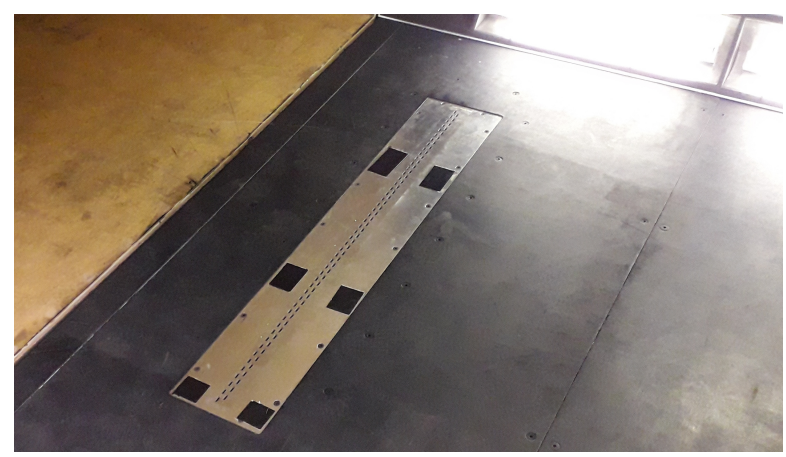

Figure 8. Boundary layer seeder at the start of the working section.

The particles are illuminated by a $200 \mathrm{~mJ}$ double pulsed Neodymium-Doped Yttrium Aluminium Garnet (Nd:YAG) laser that is passed through a plano-convex lens to spread the beam into a $\approx 0.001 \mathrm{~m}$ thick sheet. images were captured by sCMOS cameras mounted outside the flow field.

For capturing the wake at the rear of the model, one camera used a $0.035 \mathrm{~m}$ fixed f-stop lens, set to $f^{\#}=5.6$, to capture the bulk wake flow and the second used a $0.050 \mathrm{~m}$ fixed f-stop lens, also set to $f^{\#}=5.6$, to simultaneously capture the in-notch and over-body flow. The $0.050 \mathrm{~m}$ lens provides higher vector resolution locally in the region where separation is likely. When capturing the stagnation region a single camera was used with a $0.050 \mathrm{~m}$ lens and an $\mathrm{f}$-stop of $f^{\#}=5.6$. An illustration of the set up can be seen in Figure 9. 


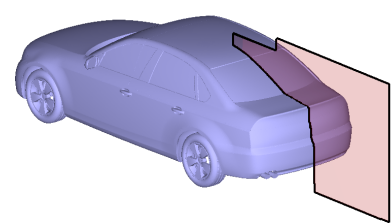

(a) Overbody and wake flow set up.
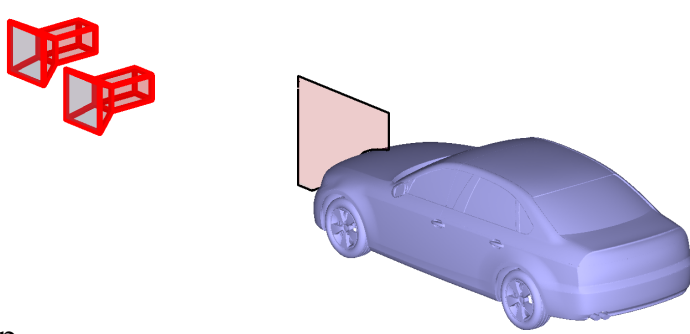

(b) Stagnation region flow set up.

Figure 9. PIV Camera set up and approximate fields of view for the $Y=0 \mathrm{~m}$ plane in the wake (a) and the stagnation $(\mathbf{b})$ regions.

A spatial calibration was performed for each camera at each plane by removing the model and using a custom machined calibration board. Although a time consuming addition to the process, removing the model allowed for the entire field of view to be calibrated fully. The resulting RMS pixel deviations are presented in Table 1. When performing the PIV at the rear of the model using two cameras, a $0.1 \mathrm{~m}$ minimum overlap between the fields of view was maintained in the $X$ direction to ensure that the fields of view can be successfully combined. This process is discussed later in this section.

Table 1. Root Mean Squared pixel deviations for each plane and camera for the PIV set up.

\begin{tabular}{lcc}
\hline Plane & Camera 1 & Camera 2 \\
\hline$Y=0 \mathrm{~m}$, Stagnation & 0.238 & - \\
$Y=0.095 \mathrm{~m}$ & 0.153 & 0.125 \\
$Y=0.0475 \mathrm{~m}$ & 0.173 & 0.168 \\
$Y=0 \mathrm{~m}$, Centreline & 0.190 & 0.168 \\
$Y=-0.0475 \mathrm{~m}$ & 0.155 & 0.169 \\
$Y=-0.095 \mathrm{~m}$ & 0.221 & 0.138 \\
$Y=-0.1425 \mathrm{~m}$ & 0.160 & 0.164 \\
$Y=-0.190 \mathrm{~m}$ & 0.181 & 0.169 \\
\hline
\end{tabular}

The measurement planes are illustrated in Figure 10 and in the wake the lateral locations range from $Y=0.095 \mathrm{~m}$ to $Y=-0.190 \mathrm{~m}$. The $Y$ position of the plane was limited in the positive direction as the curvature of the model caused significant reflections. The cameras were mounted to a rail system perpendicular to the $X Z$ plane that could be traversed in the $Y$ direction. The $X$ and $Z$ positions and the rotation of the cameras was fixed between $Y$ planes resulting in the flow field measurements being further from the model surface for the planes in the negative $Y$ direction.

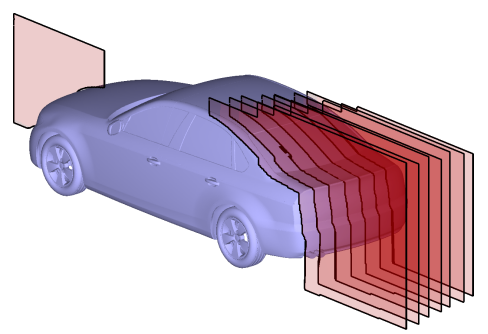

Figure 10. Illustration of PIV planes measured.

The laser inter-frame time $d t$, was tuned to produce a particle shift of approximately $25 \%$ of the final window of the PIV processing [53] whilst avoiding peak locking of the resulting vector field $[53,54]$. The $d t$ was optimised for each configuration and plane, to maximise the quality of data, the resulting $d t$ values presented in Table 2 . With two cameras capturing different parts of the flowfield at two spatial resolutions ( $0.035 \mathrm{~m}$ and $0.050 \mathrm{~m}$ lens), with large differences in flow velocity in the 
field of interest $(40 \mathrm{~m} / \mathrm{s}$ to $\approx-10 \mathrm{~m} / \mathrm{s}$ ) the inter-frame times were a compromise between optimising for peak locking and not losing particles through the plane when measuring close to the edges of the model $(Y \leq-0.1425)$ where there are significant three-dimensional flow effects. The larger variation in $d t$ for the Estateback model at the $Y=-0.1425 \mathrm{~m}$ is discussed in the results section.

Table 2. Value of $d t(\mu \mathrm{s})$ for each plane and configuration.

\begin{tabular}{lccc}
\hline Plane & Estate & Notch & Fast \\
\hline$Y=0 \mathrm{~m}$, Stagnation & 21 & 21 & 21 \\
$Y=0.095 \mathrm{~m}$ & 31 & 29 & 29 \\
$Y=0.0475 \mathrm{~m}$ & 31 & 29 & 29 \\
$Y=0 \mathrm{~m}$, Centreline & 29 & 31 & 31 \\
$Y=-0.0475 \mathrm{~m}$ & 31 & 29 & 29 \\
$Y=-0.095 \mathrm{~m}$ & 31 & 29 & 29 \\
$Y=-0.1425 \mathrm{~m}$ & 17 & 29 & 29 \\
$Y=-0.190 \mathrm{~m}$ & 29 & 29 & 29 \\
\hline
\end{tabular}

The images were pre-processed by applying a background subtraction, using a symmetric seven image long Butterworth filter, to improve the signal-to-noise ratio between the background and the particles. To aid the background subtraction the model was also masked in the images to reduce computation time.

The images were processed using an FFT algorithm in DaVis ${ }^{\circledR}$ using a multi-pass approach. The initial processing step used a large $128 \times 128$ window with a $0 \%$ window overlap, to capture the large pixel displacements in the freestream and then incrementally reduced to a final windows size of $24 \times 24$ with an overlap of $50 \%$. Between the window size reduction the vectors with a q-ratio (ratio of the highest to second highest correlation peak) of less than 1.3 were removed and interpolated to allow for the next step to continue. The interpolation to fill the gaps was not performed on the final pass.

This processing tree results in a vector resolution of $\approx 420 \mathrm{vec} / \mathrm{m}$ for the $0.035 \mathrm{~m}$ lens in the bulk wake and $\approx 620 \mathrm{vec} / \mathrm{m}$ for the $0.050 \mathrm{~m}$ lens in notch $/$ near wake. The resolution is $\approx 590 \mathrm{vec} / \mathrm{m}$ in the stagnation region. The accuracy of PIV velocity data is generally stated in terms of the confidence in the mean flow field. This can vary spatially because it is strongly determined by the fluctuations in velocity caused by the turbulence in the flow field, which is large compared to contribution to uncertainty associated with the determination of the instantaneous vectors $[55,56]$. For the flow fields in this data set the accuracy in mean velocity magnitude is estimated to be $\pm 0.2 \%$ in the freestream and $\pm 1.5 \%$ in the wake region and shear layers.

In the results presented here and the published dataset [6] the two fields of view are presented as a single plane of data achieved by merging the vector fields onto a common grid. Within the DaVis ${ }^{\circledR}$ software this is implemented by linearly interpolating all the vector fields to the finest grid spacing and then taking a mean where there is more than one vector. However, when the vector resolutions are significantly different, as they are here, this method was found to introduce banding at the edge of overlapping regions. This problem is avoided here by applying the method of Varney [57]. In this method a half sine wave weighting is applied to the edges of the field of view of each camera, with a 0 weighting at the very edge, rising to a weighting of 0.550 vectors from the edge. If the sum of the weights is less than one, then their percentage of the sum of the weights is used instead. This method results in a smoother transition between the two fields of view.

\section{Results}

As there are eight PIV measurement planes for each model configuration, there are also eight sets of accompanying balance and pressure data. The mean and standard deviations of the drag and lift coefficients are presented in Table 3. Pressure contours of the mean, RMS and standard deviation for the averages are presented in Figure 11, Figure 12 and Figure 13 respectively. Note that when making PIV measurements on the centre-line plane in the wake, $Y=0 \mathrm{~m}$, the pressure tappings were taped 
over to prevent reflections from the laser. The mean from these tappings is therefore based upon seven sets of data.

Table 3. Average force coefficients from all tests and the standard deviation of the averages from each test.

\begin{tabular}{lccc}
\hline & Estateback & Fastback & Notchback \\
\hline$\overline{C_{d}}$ & 0.334 & 0.311 & 0.312 \\
$\sigma\left(C_{d}\right)$ & 0.001 & 0.002 & 0.002 \\
\hline$\overline{C_{l}}$ & -0.022 & 0.106 & 0.095 \\
$\sigma\left(C_{l}\right)$ & 0.011 & 0.004 & 0.005 \\
\hline$\overline{C_{l f}}$ & -0.032 & 0.007 & 0.011 \\
$\sigma\left(C_{l f}\right)$ & 0.003 & 0.002 & 0.003 \\
\hline$\overline{C_{l r}}$ & 0.010 & 0.099 & 0.084 \\
$\sigma\left(C_{l r}\right)$ & 0.009 & 0.002 & 0.002 \\
\hline
\end{tabular}

It is difficult to make a direct comparison of these results with the data presented in Table A1 because there is no identical setup, and it is not always clear whether published data has been blockage corrected. The closest test cases are those of [37] who reports $C_{d}$ values of 0.303 for the estateback and 0.278 for the fastback, in both cases without a cooling flow, but blockage corrected. For reference applying a simple continuity correction to determine a corrected wind speed (Equation (6)), to our data the average value of $C_{d}$ for the estateback, fastback and notchback are $0.299,0.278$ and 0.279 respectively.

$$
\begin{array}{r}
v_{\text {corr }}=v_{\text {meas }} \cdot \frac{A_{\text {tunnel }}}{A_{\text {tunnel }}-A_{\text {model }}} \\
=v_{\text {meas }} \cdot \frac{2.489}{2.489-0.136} \\
1.058 \cdot v_{\text {meas }}
\end{array}
$$

The value of $C_{d}$ for the notchback and fastback geometries are very similar, but it is clear from the pressure distributions, Figure 11, that there are some significant differences in the flow at the rear of the model. The fastback shows quite smooth pressure recovery along the final section of the roof and down the slant while the more aggressive rear windscreen angle on the notchback shows more rapid recovery on the slant and increased pressures within the notch. So while the front lift $C_{l f}$ is similar for the two cases the notchback has significantly lower rear lift. Accurately reproducing these subtle differences are important considerations for numerical simulations.

The estateback, when compared to the notchback and fastback geometries, has a larger $C_{d}$ and lower $C_{l}$ values. While there is some pressure recovery along the roof this is relatively limited such that there is lower pressure over the larger base area evident in Figure 11. The reduction in $C_{l}$ occurs at both the front and rear of the model. The rear $C_{l r}$, is caused by reduced suction over the roof in the absence of a rear slant, and the reduction in $C_{l f}$, is due to a change in the balance of flow passing under and over the body. This difference is subtle but can be seen in the streamlines in the stagnation region in the PIV data in Figure 14. Capturing the small differences in streamline curvature in this region may be an important consideration when attempting to correctly predict lift in a CFD simulation.

The test to test variability is summarised by the standard deviation of the coefficients provided in Table 3. This variability, typical of any wind tunnel, is associated with any unaccounted for environmental conditions, overall accuracy of the experimental facility and there may also be some variation due to very long time wake dynamics, although the sampling time of $300 \mathrm{~s}$ is quite long. The standard deviations in $C_{d}$ and $C_{l f}$ are similar for each of the three geometries, but the test to test variability in $C_{l r}$, and consequently also $C_{l}$, is much larger for the estateback. The larger standard deviation in the lift for the fastback and notchback geometries compared to the drag may be associated 
with the variation seen in the test to test pressures (Figure 13) on the trailing edge of the roof and boot deck for these configurations, but equally may be because the full-scale range of lift on this balance is much larger than for drag so the absolute accuracy is poorer for lift. Although there is less test to test variability in the pressures for the estateback (Figure 13) than the other configurations, the large amount of unsteadiness on the back-light, evident in Figure 12, demonstrates that this is a much more unsteady wake; and because it is close to lift neutral at the rear, this leads to a larger test to test variation in the coefficient $C_{l r}$.

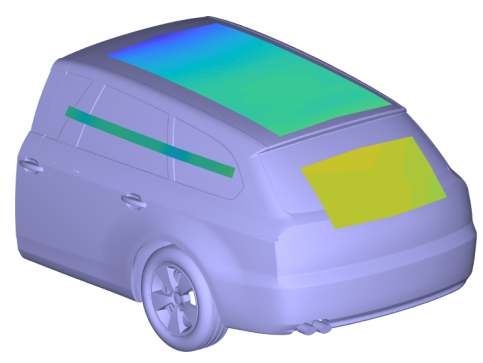

(a) Estateback

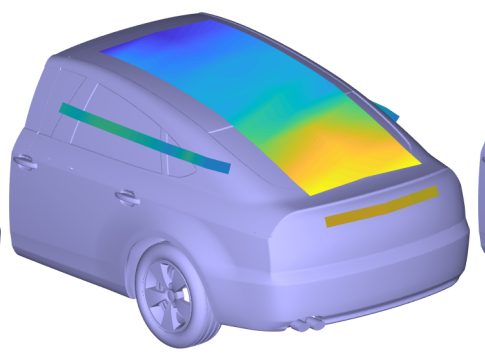

(b) Fastback

$\overline{C_{p}}$

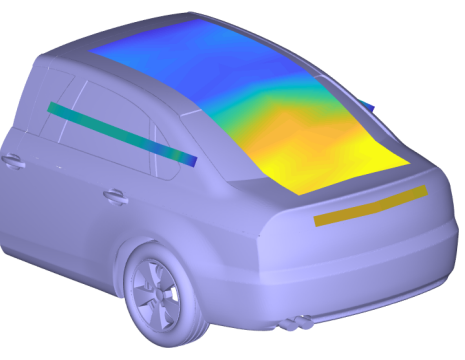

(c) Notchback

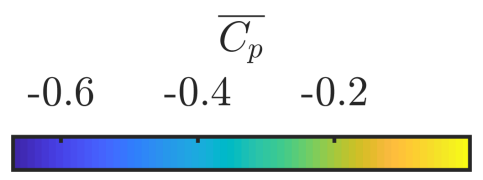

Figure 11. Mean of the surface pressures taken during the $Y=-0.190 \mathrm{~m}$ acquisition.

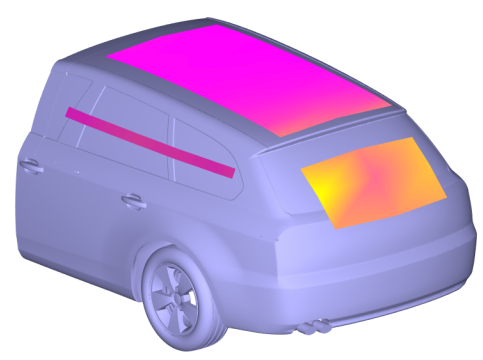

(a) Estateback

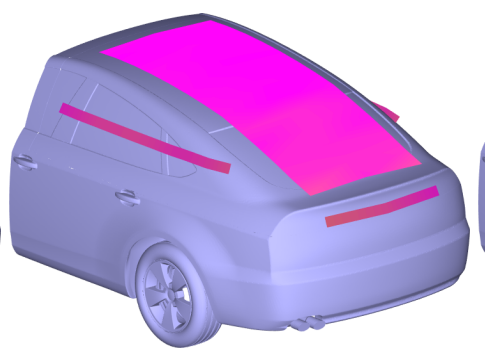

(b) Fastback

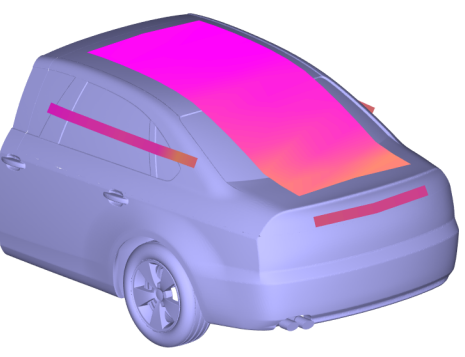

(c) Notchback

$$
\begin{array}{ccccc}
\multicolumn{2}{c}{R M S\left(C_{p}^{\prime}\right)} \\
0.01 & 0.02 & 0.03 & 0.04 & 0.05
\end{array}
$$

Figure 12. RMS of the surface pressures taken during the $Y=-0.190 \mathrm{~m}$ acquisition.

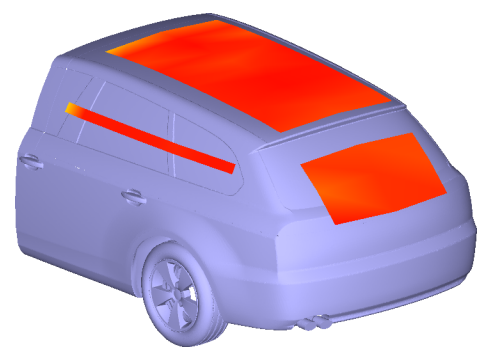

(a) Estateback

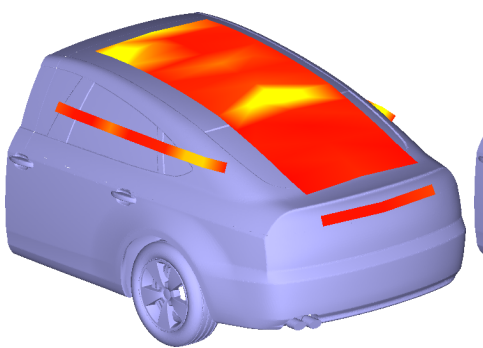

(b) Fastback

$$
\sigma\left(\overline{C_{p}}\right)
$$$$
0.01
$$

0

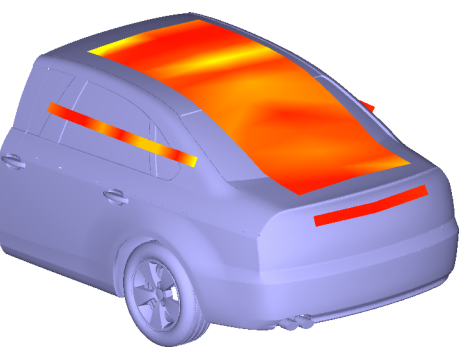

(c) Notchback

Figure 13. Standard deviation $(\sigma)$ of the mean from all pressure tests, apart from $Y=0 \mathrm{~m}$ where the centreline pressure tapings were taped over. 

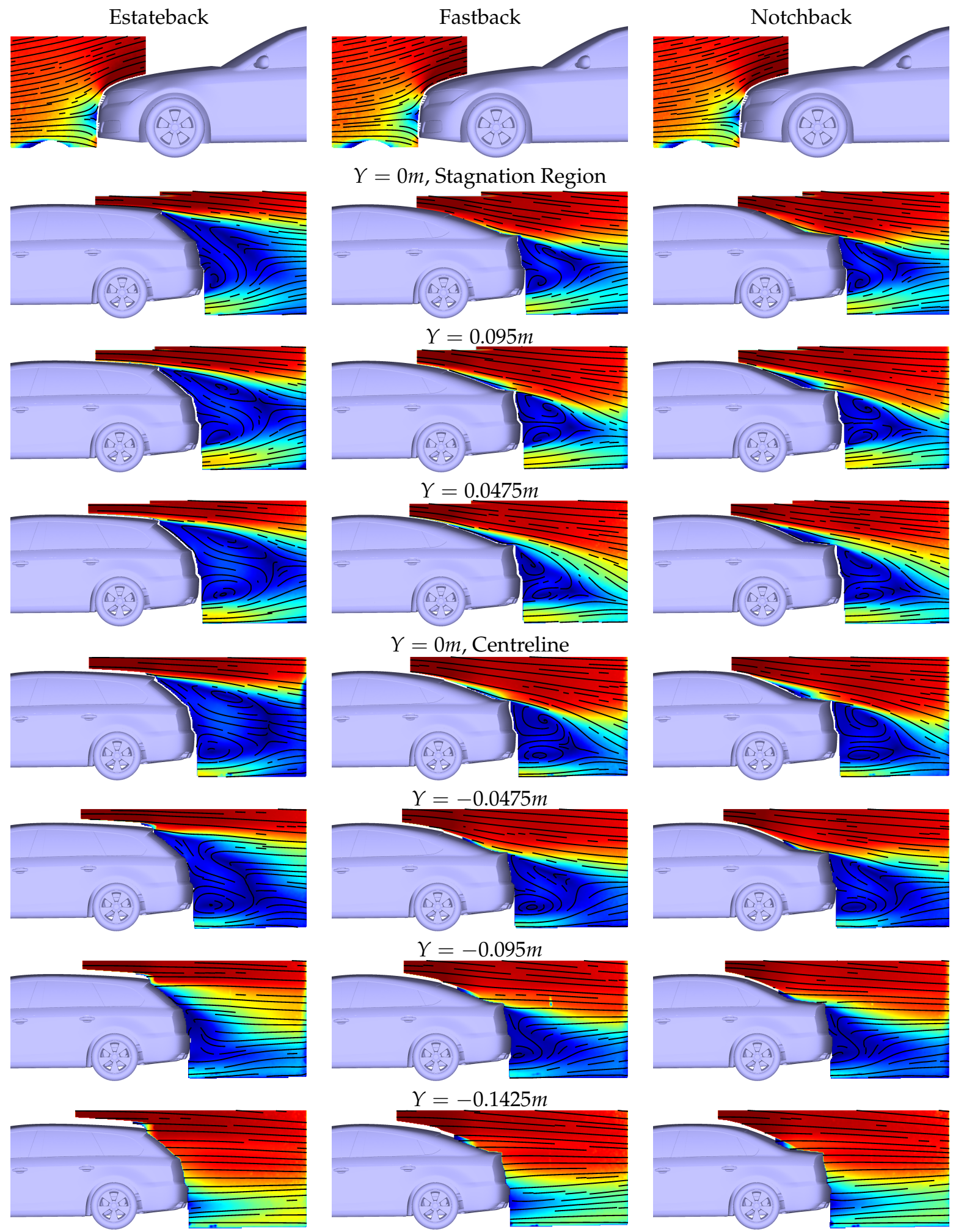

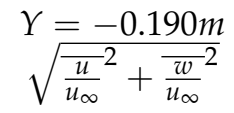

$\begin{array}{llllll}0 & 0.2 & 0.4 & 0.6 & 0.8 & 1\end{array}$

Figure 14. Side profile for all PIV planes of normalised velocity magnitude for all three DrivAer configurations tested. 
The PIV results for all three configurations are presented as mean (Figure 14) and an RMS of the fluctuation of velocity (Figure 15), normalised to the mean freestream velocity for that test. The normalisation is applied for presentation in the paper only and not to the data in the dataset [6].

Before looking at the flow-fields it is worth making some general observations regarding the quality of the PIV data. These observations are intended to assist the reader in interpreting the figures and comparing data in the dataset with computational results. At the extremities of the field of view particles can enter and leave the interrogation cells, and can bias the results or cause higher RMS values than are actually present. This effect can be seen in the most downstream portions of some cases in Figure 15. The regions of low velocity close to the model at $Y \leq-0.095 \mathrm{~m}$ in Figure 14 approximately inline with the rear of the rear wheels are artefacts of the processing and are caused by the model casting a shadow at the upstream camera. Likewise the small region on the ground plane upstream of the front of the models is not a real effect but is caused by a strong reflection of the laser from the floor.

Considering now the flow fields themselves, the stagnation regions, (Figure 14) show very limited differences between the three rear end designs, apart from the previously noted small difference for the estateback that may be responsible for the change in front lift $C_{l f}$ in Table 3.

The estateback generates a typical squareback wake with a clean separation at the sharp trailing edge of the spoiler. The pressure recovery over the roof results in some down-wash, and wake closure about $40 \%$ of the model length downstream of the base. The wake is further shortened towards the sides of the model as a consequence of in-wash. However, the flow field is not completely laterally symmetrical, although this does not appear to be reflected in the base pressures illustrated in Figure 11. There appears to be a small amount of separation on the ground plane downstream of the model that is evident most clearly in the data on the centreline $(Y=0)$, and at $Y=-0.0475 \mathrm{~m}$ and $Y=-0.095$. This can also be seen in Figure 15 in a small increase in the fluctuating velocity locally. The shear layers, emanating from the roof and underbody, thicken relatively rapidly suggesting some small scale shedding in these areas.

Although the notchback and fastback geometries produce very similar values of $C_{d}$ the differences in wake structure are clear in the PIV data. There is a small amount of separation on the slant of the fastback, present on the centreline and at $Y=+0.0475$ but less apparent on the other side of the model, though the measurements here are not as close to the surface so some separated flow may not have been captured. The separation is quite limited because there is only a small effect seen in the accompanying rms data in Figure 15, but the streamlines, particularly on the centreline suggest that there is no reattachment. Separation over the rear windscreen for the notchback geometry is clear, particularly on the centreline and at $Y= \pm 0.0475$, although the flow separates more strongly at $Y=+0.0475$ than at $Y=-0.0475$ indicating that the wake is not symmetric. This asymmetry is clearer still in Figure 15. The flow reattaches across the width of the back. although the pressure data does not show any particularly strong impingement.

The detached flow over the rear windscreen for the notchback geometry also results in a longer wake when compared to the fastback geometry, suggesting higher base pressure drag, this is counteracted by higher pressure over the rear windscreen (Figure 11) and boot-deck, combining to give the very similar overall values of $C_{d}$ despite producing different flow fields.

The streamlines for the measurements close to the rear pillars at $Y=-0.1425 \mathrm{~m}$ (Figure 14) indicate that the notchback and fastback geometries have a separated recirculating region behind the rear bumper, but the estateback does not. This was initially thought to be a problem in the setup of the PIV, but varying the inter-frame time, $d t$, over a larger range $(9 \mu \mathrm{s}-33 \mu \mathrm{s})$ did not alter the result. This suggests that there is also a significant through plane velocity locally, that cannot be captured with 2D2C PIV. The lower pressure on the base of the estateback geometry, compared to the fastback and notchback is likely to be responsible for this inflow around the bumper. The final most outboard measurement plane at $Y=-0.190 \mathrm{~m}$ lies outside of the upper glass house (see Figure 10), so is related to the lower body and bumper flow. The fastback and notchback show little difference; the estateback shows a smaller region of retarded flow consistent with the plane inboard. 

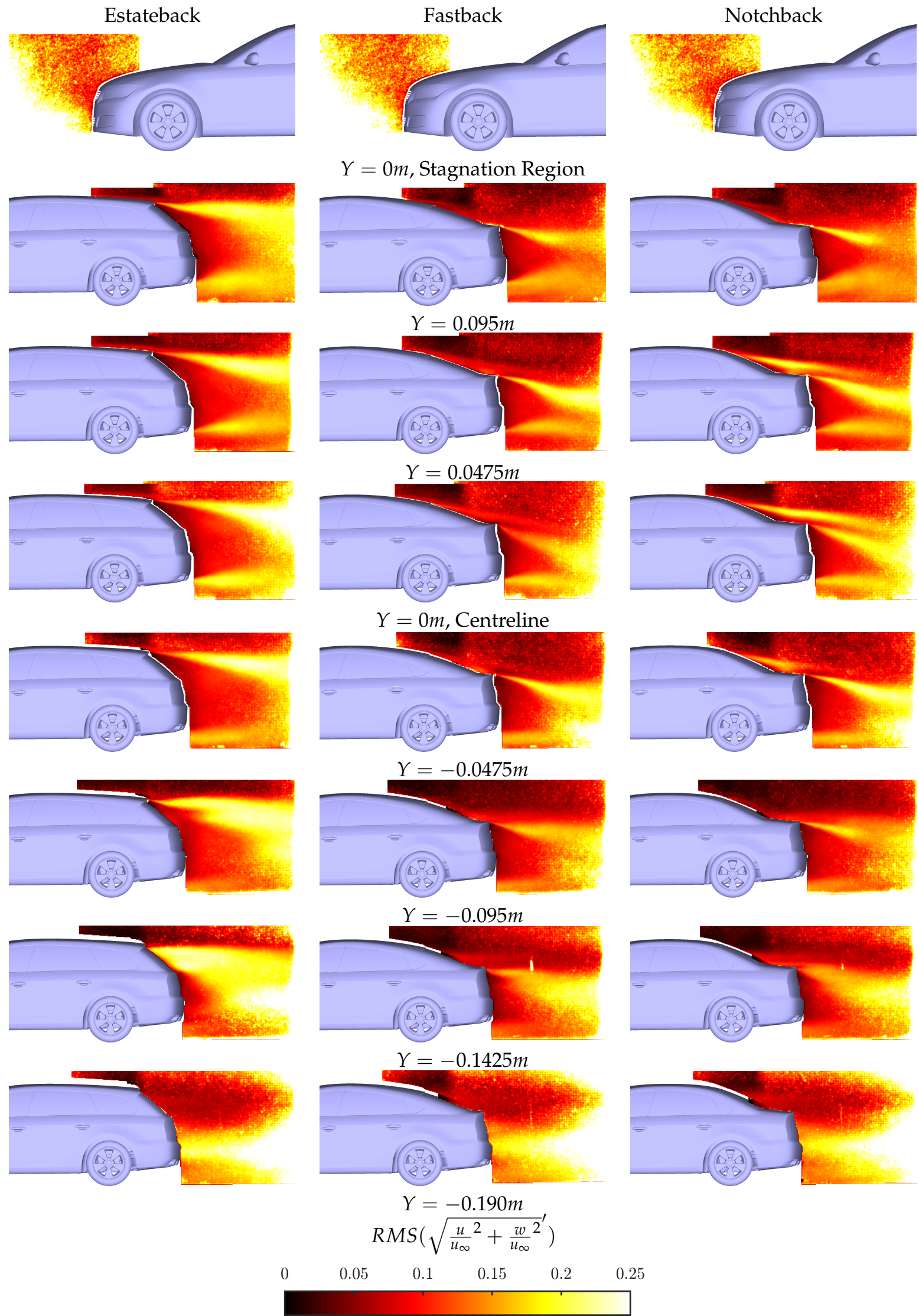

Figure 15. Side profile for all PIV planes of root mean squared of the normalised velocity magnitude fluctuations for all three DrivAer configurations tested. 


\section{Conclusions}

This paper presents force, pressure and flow field measurements for the open source DrivAer automotive test case. Comparisons are made between the three major rear geometry configurations of the estateback, fastback and notchback. The full dataset is available free access from the Loughborough University institutional repository [6].

The fastback and notchback geometries present similar overall force coefficients but significant differences in the rear end pressure distributions and flow fields. The fastback shows some limited separation around the centre line and the notchback a quite large separation bubble on the rear windscreen. The separation bubble reduces the down-wash and consequently the notchback also shows a slightly longer wake.

The estateback shows significantly different flow fields and force coefficients to the other geometries. The more bluff rear end of the geometry generates a much larger wake, resulting lower pressure on the base and a higher drag. This low pressure wake also results in a later separation on the rounded bumper geometry. A small difference in the front impingement region is responsible for significantly lower front lift than the other configurations.

All three configurations show a small degree of asymmetry in their wakes.

The data acquisition methods, model setup and geometry and the wind tunnel are described in detail to generate a transparent dataset [6] for comparison to computational simulations. Repeats of measurements are included to show test to test repeatability.

Author Contributions: Conceptualization, M.P.; methodology, M.V., M.P.; software, M.V.; validation, M.V.; formal analysis, M.V.; investigation, M.V.; resources, F.W., M.P., T.K.; data curation, M.V.; writing一original draft preparation, M.V.; writing_review and editing, M.P.; visualization, M.V.; supervision, M.P.; project administration, M.P., M.V.; funding acquisition, M.P. All authors have read and agreed to the published version of the manuscript.

Funding: This research received no external funding.

Acknowledgments: Acknowledgments go to Andrew Horsey for his help manufacturing and fitting the model into the Loughborough University Large Wind Tunnel.

Conflicts of Interest: The authors declare no conflict of interest. 
Appendix A. Previous Literature Results

Table A1. Previous DrivAer Results and Publications.

\begin{tabular}{|c|c|c|c|c|c|c|c|c|c|c|c|c|}
\hline Body & Wheels & Underbody & Cooling Flow & Mirrors & Tunnel & Scale (\%) & Blockage (\%) & Reynolds Number $\left(\times 10^{6}\right)$ & Ground Simulation & $C_{d}$ & $C_{l}$ & Citation \\
\hline Estate & Static & Smooth & $\mathrm{N}$ & $\mathrm{Y}$ & 1.4MW-Monash & 100 & 20.7 & 8 & Static & 0.291 & - & [41] \\
\hline Estate & Proprietry & Smooth & $\mathrm{N}$ & $\mathrm{Y}$ & AAWK-Audi & 40 & 3.15 & 5.2 & 1 Belt & 0.298 & -0.007 & [35] \\
\hline Fast & Proprietry & Smooth & $\mathrm{N}$ & $\bar{Y}$ & AAWK-Audi & 40 & 3.15 & 5.2 & 1 Belt & 0.251 & 0.024 & [35] \\
\hline Notch & Proprietry & Smooth & $\mathrm{N}$ & $\mathrm{Y}$ & AAWK—Audi & 40 & 3.15 & 5.2 & 1 Belt & 0.255 & 0.004 & [35] \\
\hline Estate & Proprietry & Smooth & $\mathrm{N}$ & $\mathrm{Y}$ & WTA-TU Munich & 40 & 8 & 5.2 & 1 Belt & 0.299 & -0.154 & [35] \\
\hline Fast & Proprietry & Smooth & $\mathrm{N}$ & Y & WTA-TU Munich & 40 & 8 & 5.2 & 1 Belt & 0.252 & -0.008 & [35] \\
\hline Notch & Proprietry & Smooth & $\mathrm{N}$ & $\mathrm{Y}$ & WTA-TU Munich & 40 & 8 & 5.2 & 1 Belt & 0.255 & -0.028 & {$[35,58]$} \\
\hline Fast & Proprietry & Detailed & $\mathrm{N}$ & $\mathrm{Y}$ & WTA-TU Munich & 40 & 8.3 & 4.9 & 1 Belt & 0.275 & - & [8] \\
\hline Fast & Proprietry & Detailed & $\mathrm{N}$ & $\mathrm{N}$ & WTA-TU Munich & 40 & 8.3 & 4.9 & 1 Belt & 0.261 & - & [8] \\
\hline Notch & Proprietry & Detailed & $\mathrm{N}$ & $\mathrm{Y}$ & WTA-TU Munich & 40 & 8.3 & 4.9 & 1 Belt & 0.277 & - & [8] \\
\hline Notch & Proprietry & Detailed & $\mathrm{N}$ & $\mathrm{N}$ & WTA-TU Munich & 40 & 8.3 & 4.9 & 1 Belt & 0.262 & - & [8] \\
\hline Estate & Proprietry & Detailed & $\mathrm{N}$ & $\mathrm{Y}$ & WTA-TU Munich & 40 & 8.3 & 4.9 & 1 Belt & 0.319 & - & [8] \\
\hline Estate & Proprietry & Detailed & $\mathrm{N}$ & $\mathrm{N}$ & WTA-TU Munich & 40 & 8.3 & 4.9 & 1 Belt & 0.307 & - & [8] \\
\hline Fast & Proprietry & Smooth & $\mathrm{N}$ & $\mathrm{Y}$ & WTA-TU Munich & 40 & 8.3 & 4.9 & 1 Belt & 0.243 & - & [8] \\
\hline Fast & Proprietry & Smooth & $\mathrm{N}$ & $\mathrm{N}$ & WTA-TU Munich & 40 & 8.3 & 4.9 & 1 Belt & 0.227 & - & [8] \\
\hline Notch & Proprietry & Smooth & $\mathrm{N}$ & $\mathrm{Y}$ & WTA-TU Munich & 40 & 8.3 & 4.9 & 1 Belt & 0.246 & - & [8] \\
\hline Notch & Proprietry & Smooth & $\mathrm{N}$ & $\mathrm{N}$ & WTA-TU Munich & 40 & 8.3 & 4.9 & 1 Belt & 0.232 & - & [8] \\
\hline Estate & Proprietry & Smooth & $\mathrm{N}$ & $\mathrm{Y}$ & WTA-TU Munich & 40 & 8.3 & 4.9 & 1 Belt & 0.292 & - & [8] \\
\hline Estate & Proprietry & Smooth & $\mathrm{N}$ & $\mathrm{N}$ & WTA-TU Munich & 40 & 8.3 & 4.9 & 1 Belt & 0.28 & - & [8] \\
\hline Fast & Proprietry & Detailed & $\mathrm{N}$ & $\mathrm{Y}$ & WTA-TU Munich & 40 & 8.3 & 4.9 & Static & 0.284 & - & [8] \\
\hline Fast & Proprietry & Detailed & $\mathrm{N}$ & $\mathrm{N}$ & WTA-TU Munich & 40 & 8.3 & 4.9 & Static & 0.269 & - & [8] \\
\hline Notch & Proprietry & Detailed & $\mathrm{N}$ & $\mathrm{Y}$ & WTA-TU Munich & 40 & 8.3 & 4.9 & Static & 0.286 & - & {$[8]$} \\
\hline Notch & Proprietry & Detailed & $\mathrm{N}$ & $\mathrm{N}$ & WTA-TU Munich & 40 & 8.3 & 4.9 & Static & 0.271 & - & [8] \\
\hline Estate & Proprietry & Detailed & $\mathrm{N}$ & $\mathrm{Y}$ & WTA-TU Munich & 40 & 8.3 & 4.9 & Static & 0.319 & - & [8] \\
\hline Estate & Proprietry & Detailed & $\mathrm{N}$ & $\mathrm{N}$ & WTA-TU Munich & 40 & 8.3 & 4.9 & Static & 0.306 & - & {$[8]$} \\
\hline Fast & Proprietry & Smooth & $\mathrm{N}$ & $\mathrm{Y}$ & WTA-TU Munich & 40 & 8.3 & 4.9 & Static & 0.254 & - & [8] \\
\hline Fast & Proprietry & Smooth & $\mathrm{N}$ & $\mathrm{N}$ & WTA-TU Munich & 40 & 8.3 & 4.9 & Static & 0.242 & - & [8] \\
\hline Notch & Proprietry & Smooth & $\mathrm{N}$ & $\mathrm{Y}$ & WTA-TU Munich & 40 & 8.3 & 4.9 & Static & 0.258 & - & [8] \\
\hline Notch & Proprietry & Smooth & $\mathrm{N}$ & $\mathrm{N}$ & WTA-TU Munich & 40 & 8.3 & 4.9 & Static & 0.243 & - & [8] \\
\hline Estate & Proprietry & Smooth & $\mathrm{N}$ & $\mathrm{Y}$ & WTA-TU Munich & 40 & 8.3 & 4.9 & Static & 0.296 & - & [8] \\
\hline Estate & Proprietry & Smooth & $\mathrm{N}$ & $\mathrm{N}$ & WTA-TU Munich & 40 & 8.3 & 4.9 & Static & 0.283 & - & [8] \\
\hline
\end{tabular}


Table A1. Cont.

\begin{tabular}{|c|c|c|c|c|c|c|c|c|c|c|c|c|}
\hline Body & Wheels & Underbody & Cooling Flow & Mirrors & Tunnel & Scale (\%) & Blockage (\%) & Reynolds Number $\left(\times 10^{6}\right)$ & Ground Simulation & $C_{d}$ & $C_{l}$ & Citation \\
\hline Notch & Static & Detailed & $\mathrm{N}$ & $\mathrm{N}$ & AWT_Ford & 100 & 10.6 & 11.8 & Static & 0.259 & 0.112 & [32] \\
\hline Fast & Static & Detailed & $\mathrm{N}$ & $\mathrm{N}$ & AWT_Ford & 100 & 10.6 & 11.8 & Static & 0.260 & 0.130 & [32] \\
\hline Estate & Static & Detailed & $\mathrm{N}$ & $\mathrm{N}$ & AWT_Ford & 100 & 10.6 & 11.8 & Static & 0.291 & -0.015 & [32] \\
\hline Notch & Static & Detailed & $\mathrm{N}$ & $\mathrm{N}$ & AWT_Ford & 100 & 10.6 & $\approx 6.8$ & Static & 0.261 & - & [32] \\
\hline Notch & Static & Smooth & $\mathrm{N}$ & $\mathrm{N}$ & AWT-Ford & 100 & 10.6 & 11.8 & Static & 0.233 & 0.051 & [32] \\
\hline Fast & Static & Smooth & $\mathrm{N}$ & $\mathrm{N}$ & AWT_Ford & 100 & 10.6 & 11.8 & Static & 0.230 & 0.051 & [32] \\
\hline Estate & Static & Smooth & $\mathrm{N}$ & $\mathrm{N}$ & AWT_Ford & 100 & 10.6 & 11.8 & Static & 0.273 & -0.087 & [32] \\
\hline Notch & Static & Detailed & $\mathrm{N}$ & $\mathrm{N}$ & DTF-Ford & 100 & 11.3 & $\approx 6.8$ & Static & 0.264 & - & [32] \\
\hline Notch & Static & Detailed & $\mathrm{N}$ & $\mathrm{N}$ & DTF-Ford & 100 & 11.3 & 11.8 & Static & 0.258 & - & [32] \\
\hline Notch & Static & Detailed & $\mathrm{N}$ & $\mathrm{N}$ & 1.4 MW-Monash & 100 & 16.1 & $\approx 6.8$ & Static & 0.254 & - & [32] \\
\hline Notch & Static & Detailed & $\mathrm{N}$ & $\mathrm{N}$ & 1.4 MW-Monash & 100 & 16.1 & 11.8 & Static & 0.253 & $\approx 0.1$ & [32] \\
\hline Notch & Yes & Detailed & $\mathrm{N}$ & $\mathrm{N}$ & Tongji & 100 & 7.9 & $\approx 6.8$ & 5 Belt & 0.253 & - & [32] \\
\hline Notch & Yes & Detailed & $\mathrm{N}$ & $\mathrm{N}$ & Tongji & 100 & 7.9 & 11.8 & 5 Belt & 0.244 & $\approx 0.085$ & [32] \\
\hline Notch & Yes & Detailed & $\mathrm{N}$ & $\mathrm{N}$ & Tongji & 100 & 7.9 & $\approx 15.2$ & 5 Belt & 0.24 & - & [32] \\
\hline Notch & Static & Detailed & $\mathrm{N}$ & $\mathrm{N}$ & Tongji & 100 & 7.9 & $\approx 6.8$ & Static & 0.263 & - & [32] \\
\hline Notch & Static & Detailed & $\mathrm{N}$ & $\mathrm{N}$ & Tongji & 100 & 7.9 & 11.8 & Static & 0.265 & $\approx 0.125$ & [32] \\
\hline Notch & Static & Detailed & $\mathrm{N}$ & $\mathrm{N}$ & Tongji & 100 & 7.9 & $\approx 15.2$ & Static & 0.265 & - & [32] \\
\hline Notch & Yes & Detailed & $\mathrm{N}$ & $\mathrm{N}$ & PVT-Volvo & 100 & 7.8 & $\approx 6.8$ & 5 Belt & 0.26 & - & [32] \\
\hline Notch & Yes & Detailed & $\mathrm{N}$ & $\mathrm{N}$ & PVT_Volvo & 100 & 7.8 & 11.8 & 5 Belt & 0.254 & $\approx 0.07$ & [32] \\
\hline Notch & Yes & Detailed & $\mathrm{N}$ & $\mathrm{N}$ & PVT_-Volvo & 100 & 7.8 & $\approx 15.2$ & 5 Belt & 0.248 & - & [32] \\
\hline Notch & Static & Detailed & $\mathrm{N}$ & $\mathrm{N}$ & PVT-Volvo & 100 & 7.8 & 11.8 & Static & 0.277 & $\approx 0.115$ & [32] \\
\hline Notch & Static & Detailed & $\mathrm{N}$ & $\mathrm{N}$ & PVT-Volvo & 100 & 7.8 & $\approx 15.2$ & Static & 0.278 & - & {$[32]$} \\
\hline Notch & Yes & Detailed & $\mathrm{N}$ & $\mathrm{N}$ & Windshear Inc. & 100 & 12.7 & $\approx 6.8$ & 1 Belt & 0.247 & - & [32] \\
\hline Notch & Yes & Detailed & $\mathrm{N}$ & $\mathrm{N}$ & Windshear Inc. & 100 & 12.7 & 11.8 & 1 Belt & 0.242 & $\approx 0.05$ & [32] \\
\hline Notch & Yes & Detailed & $\mathrm{N}$ & $\mathrm{N}$ & Windshear Inc. & 100 & 12.7 & $\approx 15.2$ & 1 Belt & 0.24 & - & [32] \\
\hline Notch & Static & Detailed & $\mathrm{N}$ & $\mathrm{N}$ & Windshear Inc. & 100 & 12.7 & $\approx 6.8$ & Static & 0.259 & - & [32] \\
\hline Notch & Static & Detailed & $\mathrm{N}$ & $\mathrm{N}$ & Windshear Inc. & 100 & 12.7 & 11.8 & Static & 0.271 & $\approx 0.115$ & [32] \\
\hline Notch & Static & Detailed & $\mathrm{N}$ & $\mathrm{N}$ & Windshear Inc. & 100 & 12.7 & $\approx 15.2$ & Static & 0.274 & - & [32] \\
\hline Notch & Yes & Detailed & $\mathrm{N}$ & $\mathrm{Y}$ & MWK-FKFS & 25 & - & 3.8 & 5 Belt & 0.282 & 0.073 & [42] \\
\hline Estate & Yes & Detailed & $\mathrm{N}$ & $\mathrm{Y}$ & MWK-FKFS & 25 & - & 3.8 & 5 Belt & 0.309 & -0.041 & {$[42]$} \\
\hline Fast & Yes & Detailed & $\mathrm{N}$ & Y & MWK-FKFS & 25 & - & 3.8 & 5 Belt & 0.28 & 0.09 & [42] \\
\hline Notch & Yes & Detailed & $\mathrm{Y}$ & Y & MWK-FKFS & 25 & - & 3.8 & 5 Belt & 0.289 & 0.074 & [42] \\
\hline Notch & Yes & Smooth & $\mathrm{N}$ & Y & MWK-FKFS & 25 & - & 3.8 & 5 Belt & 0.261 & 0.041 & [42] \\
\hline
\end{tabular}


Table A1. Cont.

\begin{tabular}{|c|c|c|c|c|c|c|c|c|c|c|c|c|}
\hline Body & Wheels & Underbody & Cooling Flow & Mirrors & Tunnel & Scale $(\%)$ & Blockage (\%) & Reynolds Number $\left(\times 10^{6}\right)$ & Ground Simulation & $C_{d}$ & $C_{l}$ & Citation \\
\hline Fast & Proprietry & Detailed & $\mathrm{N}$ & $\mathrm{Y}$ & WTA-TU Munich & 40 & 8.3 & 5.2 & 1 Belt & 0.274 & - & [7] \\
\hline Notch & Proprietry & Detailed & $\mathrm{N}$ & $\mathrm{Y}$ & WTA-TU Munich & 40 & 8.3 & 5.2 & 1 Belt & 0.275 & - & [7] \\
\hline Estate & Proprietry & Detailed & $\mathrm{N}$ & $\mathrm{Y}$ & WTA-TU Munich & 40 & 8.3 & 5.2 & 1 Belt & 0.314 & - & [7] \\
\hline Fast & Proprietry & Generic & $\mathrm{N}$ & $\mathrm{Y}$ & WTA_TU Munich & 40 & 8.3 & 5.2 & 1 Belt & 0.253 & - & [7] \\
\hline Notch & Proprietry & Generic & $\mathrm{N}$ & $\mathrm{Y}$ & WTA-TU Munich & 40 & 8.3 & 5.2 & 1 Belt & 0.257 & - & [7] \\
\hline Estate & Proprietry & Generic & $\mathrm{N}$ & $\mathrm{Y}$ & WTA-TU Munich & 40 & 8.3 & 5.2 & 1 Belt & 0.302 & - & [7] \\
\hline Fast & Proprietry & Smooth & $\mathrm{N}$ & $\mathrm{N}$ & WTA-TU Munich & 40 & 8.3 & 5.2 & 1 Belt & 0.228 & - & [7] \\
\hline Notch & Proprietry & Smooth & $\mathrm{N}$ & $\mathrm{N}$ & WTA-TU Munich & 40 & 8.3 & 5.2 & 1 Belt & 0.233 & - & [7] \\
\hline Estate & Proprietry & Smooth & $\mathrm{N}$ & $\mathrm{N}$ & WTA-TU Munich & 40 & 8.3 & 5.2 & 1 Belt & 0.28 & - & [7] \\
\hline Fast & Proprietry & Smooth & $\mathrm{N}$ & Y & WTA-TU Munich & 40 & 8.3 & 5.2 & 1 Belt & 0.247 & - & [7] \\
\hline Notch & Proprietry & Smooth & $\mathrm{N}$ & $\mathrm{Y}$ & WTA-TU Munich & 40 & 8.3 & 5.2 & 1 Belt & 0.252 & - & [7] \\
\hline Estate & Proprietry & Smooth & $\mathrm{N}$ & $\mathrm{Y}$ & WTA-TU Munich & 40 & 8.3 & 5.2 & 1 Belt & 0.296 & - & [7] \\
\hline Fast & Proprietry & Detailed & $\mathrm{N}$ & $\mathrm{Y}$ & WTA-TU Munich & 40 & 8.3 & 5.2 & Static & 0.272 & - & [7] \\
\hline Notch & Proprietry & Detailed & $\mathrm{N}$ & $\mathrm{Y}$ & WTA-TU Munich & 40 & 8.3 & 5.2 & Static & 0.272 & - & [7] \\
\hline Estate & Proprietry & Detailed & $\mathrm{N}$ & Y & WTA-TU Munich & 40 & 8.3 & 5.2 & Static & 0.303 & - & [7] \\
\hline Fast & Proprietry & Generic & $\mathrm{N}$ & $\mathrm{Y}$ & WTA-TU Munich & 40 & 8.3 & 5.2 & Static & 0.257 & - & [7] \\
\hline Notch & Proprietry & Generic & $\mathrm{N}$ & $\mathrm{Y}$ & WTA-TU Munich & 40 & 8.3 & 5.2 & Static & 0.257 & - & [7] \\
\hline Estate & Proprietry & Generic & $\mathrm{N}$ & $\mathrm{Y}$ & WTA-TU Munich & 40 & 8.3 & 5.2 & Static & 0.292 & - & [7] \\
\hline Fast & Proprietry & Smooth & $\mathrm{N}$ & $\mathrm{N}$ & WTA-TU Munich & 40 & 8.3 & 5.2 & Static & 0.238 & - & [7] \\
\hline Notch & Proprietry & Smooth & $\mathrm{N}$ & $\mathrm{N}$ & WTA-TU Munich & 40 & 8.3 & 5.2 & Static & 0.24 & - & [7] \\
\hline Estate & Proprietry & Smooth & $\mathrm{N}$ & $\mathrm{N}$ & WTA-TU Munich & 40 & 8.3 & 5.2 & Static & 0.278 & - & [7] \\
\hline Fast & Proprietry & Smooth & $\mathrm{N}$ & $\mathrm{Y}$ & WTA-TU Munich & 40 & 8.3 & 5.2 & Static & 0.249 & - & [7] \\
\hline Notch & Proprietry & Smooth & $\mathrm{N}$ & $\mathrm{Y}$ & WTA-TU Munich & 40 & 8.3 & 5.2 & Static & 0.251 & - & [7] \\
\hline Estate & Proprietry & Smooth & $\mathrm{N}$ & $\mathrm{Y}$ & WTA-TU Munich & 40 & 8.3 & 5.2 & Static & 0.286 & - & [7] \\
\hline Fast & No & Smooth & $\mathrm{N}$ & $\mathrm{N}$ & WTA-TU Munich & 40 & 8.3 & 5.2 & 1 Belt & 0.117 & -0.345 & {$[7,33]$} \\
\hline Notch & No & Smooth & $\mathrm{N}$ & $\mathrm{N}$ & WTA-TU Munich & 40 & 8.3 & 5.2 & 1 Belt & 0.129 & -0.37 & {$[7,33]$} \\
\hline Estate & No & Smooth & $\mathrm{N}$ & $\mathrm{N}$ & WTA-TU Munich & 40 & 8.3 & 5.2 & 1 Belt & 0.192 & -0.494 & {$[7,33]$} \\
\hline Fast & No & Smooth & $\mathrm{N}$ & $\mathrm{N}$ & WTA-TU Munich & 40 & 8.3 & 5.2 & Static & 0.116 & -0.295 & {$[7,33]$} \\
\hline Notch & No & Smooth & $\mathrm{N}$ & $\mathrm{N}$ & WTA-TU Munich & 40 & 8.3 & 5.2 & Static & 0.127 & -0.319 & {$[7,33]$} \\
\hline Estate & No & Smooth & $\mathrm{N}$ & $\mathrm{N}$ & WTA-TU Munich & 40 & 8.3 & 5.2 & Static & 0.19 & -0.446 & {$[7,33]$} \\
\hline Fast & Proprietry & Smooth & $\mathrm{N}$ & $\mathrm{N}$ & WTA-TU Munich & 40 & 8.3 & 5.2 & 1 Belt & 0.244 & -0.031 & [33] \\
\hline Notch & Proprietry & Smooth & $\mathrm{N}$ & $\mathrm{N}$ & WTA-TU Munich & 40 & 8.3 & 5.2 & 1 Belt & 0.247 & -0.014 & [33] \\
\hline Estate & Proprietry & Smooth & $\mathrm{N}$ & $\mathrm{N}$ & WTA-TU Munich & 40 & 8.3 & 5.2 & 1 Belt & 0.291 & -0.146 & [33] \\
\hline Fast & Proprietry & Smooth & $\mathrm{N}$ & $\mathrm{N}$ & WTA-TU Munich & 40 & 8.3 & 5.2 & Static & 0.245 & -0.003 & [33] \\
\hline Notch & Proprietry & Smooth & $\mathrm{N}$ & $\mathrm{N}$ & WTA-TU Munich & 40 & 8.3 & 5.2 & Static & 0.246 & 0.002 & [33] \\
\hline Estate & Proprietry & Smooth & $\mathrm{N}$ & $\mathrm{N}$ & WTA-TU Munich & 40 & 8.3 & 5.2 & Static & 0.282 & -0.123 & [33] \\
\hline
\end{tabular}


Table A1. Cont.

\begin{tabular}{|c|c|c|c|c|c|c|c|c|c|c|c|c|}
\hline Body & Wheels & Underbody & Cooling Flow & Mirrors & Tunnel & Scale $(\%)$ & Blockage (\%) & Reynolds Number $\left(\times 10^{6}\right)$ & Ground Simulation & $C_{d}$ & $C_{l}$ & Citation \\
\hline Fast & No & Smooth & $\mathrm{N}$ & Y & 8x6WT_Cranfield & 35 & 10.2 & $2.1-4.2$ & 1 Belt & $\approx 0.305$ & $-0.75--0.84$ & [46] \\
\hline Notch & Static & Detailed & $\mathrm{N}$ & $\mathrm{Y}$ & MWK-FKFS & 25 & - & 3.2 & Static & 0.278 & - & [37] \\
\hline Estate & Static & Detailed & $\mathrm{N}$ & $\mathrm{Y}$ & MWK—FKFS & 25 & - & 3.2 & Static & 0.303 & - & [37] \\
\hline Fast & Static & Smooth & $\mathrm{N}$ & $\mathrm{Y}$ & MWK-TU Berlin & 25 & 5.5 & 2.8 & False floor & 0.249 & 0.057 & {$[38]$} \\
\hline Fast & Static & Smooth & $\mathrm{N}$ & $\mathrm{Y}$ & MWK-TU Berlin & 25 & 5.4 & 3.2 & False floor & 0.258 & -0.096 & [39] \\
\hline Notch & Static & Smooth & $\mathrm{N}$ & Y & MWK-TU Berlin & 25 & 5.4 & 3.2 & False floor & 0.254 & -0.107 & [39] \\
\hline Notch & Static & Smooth & $\mathrm{N}$ & $Y$ & MWK-TU Berlin & 25 & 5.4 & 3 & False floor & - & - & [40] \\
\hline Notch & Yes & Detailed & $\mathrm{N}$ & $\mathrm{Y}$ & MWK-FKFS & 25 & - & 4.6 & 5 Belt & 0.277 & 0.059 & [34] \\
\hline Estate & Yes & Detailed & $\mathrm{N}$ & Y & MWK-FKFS & 25 & - & 4.6 & 5 Belt & 0.312 & -0.059 & [34] \\
\hline Notch & Yes & Detailed & Y & Y & MWK-FKFS & 25 & - & 4.6 & 5 Belt & 0.284 & $\approx 0.055$ & [34] \\
\hline Estate & Yes & Detailed & Y & Y & MWK-FKFS & 25 & - & 4.6 & 5 Belt & 0.322 & $\approx-0.055$ & [34] \\
\hline
\end{tabular}




\section{Appendix B. Dataset README File (V1.0)}

This is the README file for the dataset for the $25 \%$ scale DrivAer model, collated by Max Varney (https:/ / www.linkedin.com/in/max-varney/) on 2020/04/07.

Data was collected in the Large Wind Tunnel at Loughborough University, a $2.5 \mathrm{~m}^{2}$, closed working section, fixed ground open return tunnel. Details of the tunnel can be found in: https://repository.lboro.ac.uk/articles/ journal_contribution/Design_methodology _and_performance_of_an_indraft_wind_tunnel/9224171.

The CAD geometry for the mounting hardware and the wind tunnel are all included in the dataset as ASCII stl files, with the units in $\mathrm{m}$. The CAD geometry of the DrivAer model has not been duplicated for this dataset, instead the full scale model can be found at: https://www.mw.tum.de/en/aer/research-groups/automotive/drivaer/.

Photos of the set up and some unique model dimensions are also included. The model was supplied by FKFS and is a $25 \%$ scale DrivAer model with three backs, the estate, fast and notchback variants. The model included the 5 spoke wheels, complex underbody, wing mirrors, the drivetrain, an open front grill and a porous radiator. As the model is not symmetric, in the engine bay and on the underside, it was set at a geometric 0 yaw condition as measured in the wind tunnel. This is estimated to be \pm 0.1 degrees.

No corrections (for example blockage) have been applied to the data. All the data is presented in SI units and all measurements are from the origin (mid-track, mid-wheelbase on the tunnel floor) with $\mathrm{x}$ positive downstream and $\mathrm{z}$ positive up, using the right hand rule to find positive $\mathrm{y}$.

The data is split into '_Mean' and '_Instantaneous' for each measurement type (Force, Pressure, Flow Field). All the data was taken during the same test session with a total sample time of $300 \mathrm{~s}$ typically and $100 \mathrm{~s}$ for the measurements in the stagnation region. The different data sets are not correlated with each other in time. The Force data was sampled at $300 \mathrm{~Hz}$, Pressure data at $260 \mathrm{~Hz}$ and the Flow Field data at $5 \mathrm{~Hz}$. The data presented in the '_Mean' folders is the arithmetic mean of that presented in the '_Instantaneous' folders.

All the '_Mean' folders contain Comma Separated Variable (csv) files, for ease of parsing with your desired programming language, and the same data is provided in a dat file that is set up to be read into TecPlot. The csv format was used to reduce size and complexity for the '_Instantaneous' data. Example MATLAB code has been provided (tested in 2018a) that reads both the '_Mean' and '_Instantaneous' csv files for the pressure and flow field measurements, plotting them accordingly.

The 'Force_Mean' folder contains 3 .csv files, one for each configuration (fast/estate/notch) with the mean values for the force data taken at each flow field plane. The folder also contains a dat file for each plane and configuration. Both file types include the velocity, ambient temperature, ambient pressure, calculated air density, yaw angle, the 3 force and 3 moments (taken about mid-wheelbase mid-track and on the tunnel floor), the model frontal area, model wheelbase, the calculated force and moment coefficients.

The 'Force_Instantaneous' folder contains a .csv file for each configuration and each flow field measurement with the same variables as the mean folder apart from the coefficients. Each row is an instance in time.

The 'Pressure_Mean' folder contains two sets of .csv files. '_Tapping_Map', presents the $x, y$ and $\mathrm{z}$ positions of the pressure tappings, the group that they belong to (1 - Roof, 2/3 - Side Glass, 4 - Base) and the associated pressure tapping number. '_Averages', contains the mean, '_MeanCp', and RMS of the deviation, '_RMSC $\mathrm{p}^{\prime}$, for each flow field plane. The flow field planes and the mean/RMS are defined in the Data_Description column. The additional columns in this file are for the individual pressure tappings.

The 'Pressure_Instantaneous' folder contains a .csv file for each configuration and each flow field measurement. It also contains the same'_Tapping_Map' csv files provide with the mean pressures to prevent the need to download both datasets. In this instance each column is a pressure tapping location and each row in a time instance. 
The 'FlowField_Mean' folder contains a .csv file for each configuration and plane. Each .csv file includes the $\mathrm{x}, \mathrm{y}$ and $\mathrm{z}$ coordinate of every vector, the mean and rms of the $\mathrm{u}$ and $\mathrm{w}$ components and the velocity magnitude. Invalid vectors are marked in the dataset with a value of -9999 at the XYZ location (Invalid vectors arise in experimental data due to seeding, image quality or processing problems). The FlowField_Example_Code hides the invalid vectors during plotting.

The 'FlowField_Instantaneous' folder contains the same file structure as 'FlowField_Mean' but with the columns representing time steps, indicated by the column header. A simple way to read this is demonstrated in FlowField_Example_Code.

\section{References}

1. Wood, D.; Passmore, M.A.; Perry, A.K. Experimental Data for the Validation of Numerical Methods - SAE Reference Notchback Model. SAE Int. J. Passeng. Cars Mech. Syst. 2014, 7, 145-154. [CrossRef]

2. Nader, A.; Islam, A.; Thornber, B. A Comparative Aerodynamic Investigation of a $20^{\circ}$ SAE Notchback Model. Appl. Mech. Mater. 2016, 846, 79-84. [CrossRef]

3. Törnell, J. PANS Prediction of Passenger Vehicle Flows. Master's Thesis, Chalmers University of Technology: Göteborg, Sweden, 2016.

4. Islam, A.; Thornber, B. Development and Application of a novel RANS and Implicit les Hybrid Turbulence Model for Automotive Aerodynamics. SAE Technol. Pap. 2016, [CrossRef]

5. Islam, A.; Thornber, B. High-order detached-eddy simulation of external aerodynamics over an SAE notchback model. Aeronaut. J. 2017, 121, 1342-1367. [CrossRef]

6. Varney, M.; Passmore, M.; Wittmeier, F.; Kuthada, T. DrivAer Experimental Aerodynamic Dataset, 2020. Available online: https://repository.lboro.ac.uk/articles/dataset/DrivAer_Experimental_Aerodynamic_ Dataset/12881213 (accessed on 1 October 2020).

7. Mack, S.; Indinger, T.; Adams, N.A.; Blume, S.; Unterlechner, P. The Interior Design of A 40 Scaled Drivaer Body and First Experimental Results. In Proceedings of the ASME 2012 Fluids Engineering Division SummerMeeting, American Society of Mechanical Engineers, Rio Grande, PR, USA, 8-12 July 2012.

8. Heft, A.I.; Indinger, T.; Adams, N.A. Introduction of a new realistic generic car model for aerodynamic investigations. SAE Technol. Pap. 2012, [CrossRef]

9. Ashton, N.; Revell, A. Comparison of RANS and des methods for the DrivAer automotive body. SAE Technol. Pap. 2015, [CrossRef]

10. Jakirlic, S.; Kutej, L.; Hanssmann, D.; Basara, B.; Tropea, C. Eddy-resolving Simulations of the Notchback 'DrivAer' Model: Influence of Underbody Geometry and Wheels Rotation on Aerodynamic Behaviour. SAE Technol. Pap. 2016, [CrossRef]

11. Howell, J.; Forbes, D.; Passmore, M.; Page, G. The Effect of a Sheared Crosswind Flow on Car Aerodynamics. SAE Int. J. Passeng. Cars Mech. Syst. 2017, 10, [CrossRef]

12. Jungmann, J.; Schütz, T.; Jakirlic, S.; Tropea, C. Flow past a DrivAer body in a scaled wind tunnel: Computational study by a reference to a complementary experiment. In Proceedings of the IMechE International Conference on Vehicle Aerodynamics, Coventry, UK, 21-22 September 2016.

13. Peters, B.C.; Uddin, M.; Bain, J.; Curley, A.; Henry, M. Simulating DrivAer with Structured Finite Difference Overset Grids. SAE Technol. Pap. 2015, [CrossRef]

14. Fields, V.; E-mail, G.; Ag, A. Online Dynamic Mode Decomposition Methods for the Investigation of Unsteady Aerodynamics of the DrivAer Model (Second Report). Int. J. Automot. Eng. 2018, 9, 72-78.

15. Soares, R.F.; Garry, K.P.; Holt, J. Comparison of the Far-Field Aerodynamic Wake Development for Three DrivAer Model Configurations Using a Cost-Effective RANS Simulation. SAE Technol. Pap. 2017, 2017-March, 4-6.

16. Guilmineau, E. Numerical Simulations of Flow around a Realistic Generic Car Model. SAE Int. J. Passeng. Cars Mech. Syst. 2014, 7, 646-653. [CrossRef]

17. Ashton, N.; West, A.; Lardeau, S.; Revell, A. Assessment of RANS and DES methods for realistic automotive models. Comput. Fluids 2016, 128, 1-15. [CrossRef]

18. Karpouzas, G.K.; Papoutsis-Kiachagias, E.M.; Schumacher, T.; de Villiers, E.; Giannakoglou, K.C.; Othmer, C. Adjoint Optimization for Vehicle External Aerodynamics. Int. J. Automot. Eng. 2016, 7, 1-7. 
19. Guilmineau, E. Numerical simulations of ground simulation for a realistic generic car model. Am. Soc. Mech. Eng. Fluids Eng. Div. FEDSM 2014, 1C, 1-10.

20. Ekman, P.; Larsson, T.; Virdung, T.; Karlsson, M. Accuracy and Speed for Scale-Resolving Simulations of the DrivAer Reference Model. Available online: https:/ /www.sae.org/publications/technical-papers / content/ 2019-01-0639 / (accessed on 1 October 2020).

21. Shaharuddin, N.H.; Ali, M.S.M.; Mansor, S.; Muhamad, S.; Salim, S.A.Z.S.; Usman, M. Flow simulations of generic vehicle model SAE type 4 and DrivAer Fastback using OpenFOAM. J. Adv. Res. Fluid Mech. Therm. Sci. 2017, 37, 18-31.

22. Shaharuddin, N.H.; Ali, M.S.M.; Mansor, S.; Muhamad, S.; Zaki, S.A. Numerical study for flow over a realistic generic model, DrivAer, using URANS. J. Adv. Res. Fluid Mech. Therm. Sci. 2018, 48, 183-195.

23. Yang, Z.F.; Li, S.H.; Liu, A.M.; Yu, Z.; Zeng, H.J.; Li, S.W. Simulation study on energy saving of passenger car platoons based on DrivAer model. Energy Sources A Recovery Util. Environ. Eff. 2019, 41, 3076-3084. [CrossRef]

24. Scardigli, A.; Arpa, R.; Lombardi, E.; Telib, H. Aerodynamic shape optimization through mesh morphing and model order reduction. In Proceedings of the Third International Conference in Numerical and Experimental Aerodynamics of Road Vehicles and Trains, Milan, Italy, 13-15 June 2018; pp. 1-4.

25. Matsumoto, D.; Haag, L.; Indinger, T. Investigation of the unsteady external and underhood airflow of the drivaer model by dynamic mode decomposition methods. Int. J. Automot. Eng. 2017, 8, 55-62. [CrossRef]

26. Forbes, D.C.; Page, G.J.; Passmore, M.A.; Gaylard, A.P. A Fully Coupled, 6 Degree-of-Freedom, Aerodynamic and Vehicle Handling Crosswind Simulation using the DrivAer Model. SAE Int. J. Passeng. Cars Mech. Syst. 2016, 9, 710-722. [CrossRef]

27. Cho, J.; Park, J.; Yee, K.; Kim, H.L. Comparison of Various Drag Reduction Devices and Their Aerodynamic Effects on the DrivAer Model. SAE Int. J. Passeng. Cars Mech. Syst. 2018, 11, 225-237. [CrossRef]

28. Rüttgers, M.; Park, J.; You, D. Large-eddy simulation of a turbulent flow over the DrivAer fastback vehicle model. J. Wind Eng. Ind. Aerodyn. 2018, 186, 123-138.

29. Good, G.L.; Annetts, I.; Quilter, S.; Cross, M.; Lewis, R. The design of systematic add-on configuration changes for the DrivAer body and their aerodynamic characteristics. In Proceedings of the IMechE International Conference on Vehicle Aerodynamics, Coventry, UK, 21-22 September 2016.

30. Bonitz, S.; Broniewicz, A.; Larsson, L.; Löfdahl, L. Flow structure identification over a notchback vehicle. In Proceedings of the IMechE International Conference on Vehicle Aerodynamics, Coventry, UK, 21-22 September 2016.

31. Wang, S.; Avadiar, T.; Thompson, M.C.; Burton, D. Effect of moving ground on the aerodynamics of a generic automotive model: The DrivAer-Estate. J. Wind Eng. Ind. Aerodyn. 2019, 195, 104000. [CrossRef]

32. James, T.; Krueger, L.; Lentzen, M.; Woodiga, S.; Chalupa, K.; Hupertz, B.; Lewington, N. Development and Initial Testing of a Full-Scale DrivAer Generic Realistic Wind Tunnel Correlation and Calibration Model. SAE Int. J. Passeng. Cars Mech. Syst. 2018, 11, 353-367. [CrossRef]

33. Miao, L.; Mack, S.; Indinger, T. Experimental and Numerical Investigation of Automotive Aerodynamics Using DrivAer Model. In Proceedings of the ASME 2015 International Design Engineering Technical Conferences and Computers and Information in Engineering Conference, Boston, MA, USA, 2-5 August 2015; p. V003T01A039.

34. Wittmeier, F.; Kuthada, T. Open Grille DrivAer Model - First Results. SAE Int. J. Passeng. Cars Mech. Syst. 2015, 8, 252-260. [CrossRef]

35. Collin, C.; Mack, S.; Indinger, T.; Mueller, J. A Numerical and Experimental Evaluation of Open Jet Wind Tunnel Interferences using the DrivAer Reference Model. SAE Int. J. Passeng. Cars Mech. Syst. 2016, 9, 657-679. [CrossRef]

36. Stoll, D. Active Crosswind Generation and Its Effect on the Unsteady Aerodynamic Vehicle Properties Determined in an Open Jet Wind Tunnel. SAE Int. J. Passeng. Cars Mech. Syst. 2018, 11, 1-17. [CrossRef]

37. Stoll, D.; Schoenleber, C.; Wittmeier, F.; Kuthada, T.; Wiedemann, J. Investigation of Aerodynamic Drag in Turbulent Flow Conditions. Sae Int. J. Passeng. Cars Mech. Syst. 2016, 9, 173-187. [CrossRef]

38. Strangfeld, C.; Wieser, D.; Schmidt, H.J.; Woszidlo, R.; Nayeri, C.; Paschereit, C. Experimental study of baseline flow characteristics for the realistic car model DrivAer. SAE Technol. Pap. 2013, 2. [CrossRef] 
39. Wieser, D.; Schmidt, H.J.; Müller, S.; Strangfeld, C.; Nayeri, C.; Paschereit, C. Experimental Comparison of the Aerodynamic Behavior of Fastback and Notchback DrivAer Models. SAE Int. J. Passeng. Cars Mech. Syst. 2014, 7, 682-691. [CrossRef]

40. Wieser, D.; Lang, H.; Nayeri, C.; Paschereit, C. Manipulation of the Aerodynamic Behavior of the DrivAer Model with Fluidic Oscillators. SAE Int. J. Passeng. Cars Mech. Syst. 2015, 8, 687-702. [CrossRef]

41. Avadiar, T.; Thompson, M.C.; Sheridan, J.; Burton, D. Characterisation of the wake of the DrivAer estate vehicle. J. Wind Eng. Ind. Aerodyn. 2018, 177, 242-259. [CrossRef]

42. John, M.; Buga, S.D.; Monti, I.; Kuthada, T.; Wittmeier, F.; Gray, M.; Laurent, V. Experimental and Numerical Study of the DrivAer Model Aerodynamics. Available online: https:/ /www.sae.org/publications/technicalpapers / content/2018-01-0741/ (accessed on 1 October 2020).

43. Avadiar, T.; Thompson, M.C.; Sheridan, J.; Burton, D. An investigation into the influence of reduced Reynolds number in experiments on the wake of a realistic passenger vehicle. In Proceedings of the Third International Conference in Numerical and Experimental Aerodynamics of Road Vehicles and Trains, Milan, Italy, 13-15 June 2018.

44. Wieser, D.; Nayeri, C.N.; Paschereit, C.O. Wake structures and surface patterns of the drivaer notchback car model under side wind conditions. Energies 2020, 13, 320. [CrossRef]

45. Avadiar, T.; Thompson, M.C.; Sheridan, J.; Burton, D. The influence of reduced Reynolds number on the wake of the DrivAer estate vehicle. J. Wind Eng. Ind. Aerodyn. 2019, 188, 207-216. [CrossRef]

46. Soares, R.F.; Knowles, A.; Goñalons Olives, S.; Garry, K.; Holt, J. On the Aerodynamics of an Enclosed-Wheel Racing Car: An Assessment and Proposal of Add-On Devices for a Fourth, High-Performance Configuration of the DrivAer Model. Available online: https:/ / dspace.lib.cranfield.ac.uk/handle/1826/13163 (accessed on 1 October 2020).

47. Johl, G. The Design and Performance of a 1.9mx1.3m Indraft Wind Tunnel. Ph.D. Thesis, Aeronautical and Automotive Engineering, Loughborough University, Loughborough, UK, 2010.

48. DrivAer Model; Technical University of Munich: München, Germany, 2012.

49. Perry, A.K.; Pavia, G.; Passmore, M.; Perry, A.K.; Passmore, M. Influence of short rear end tapers on the wake of a simplified square-back vehicle: Wake topology and rear drag. Exp. Fluids 2016, 57, 1-17. [CrossRef]

50. Pavia, G.; Varney, M.; Passmore, M.; Almond, M. Three dimensional structure of the unsteady wake of an axisymmetric body. Phys. Fluids 2019, 31, 025113. [CrossRef]

51. Vehicle Aerodynamics Terminology J1594-199412. Available online: https://www.sae.org/standards/ content/j1594_199412/ (accessed on 1 October 2020).

52. Wood, D. The Effect of Rear Geometry Changes on the Notchback Flow Field. Ph.D. Thesis, Loughborough University, Loughborough, UK, 2015.

53. Adrian, L.; Adrian, R.J.; Westerweel, J. Particle Image Velocimetry; Cambridge Aerospace Series; Cambridge University Press: Cambridge, UK, 2011.

54. Overmars, E.F.J.; Warncke, N.G.W.; Poelma, C.; Westerweel, J. Bias errors in PIV: The pixel locking effect revisited. In Proceedings of the 15th International. Symposium Applications Laser Techniques to fluid Mechanics, Lisbon, portugal, 5-8 July 2010; pp. 5-8.

55. Littlewood, R. Novel Methods of Drag Reduction for Squareback Road Vehicles. Ph.D. Thesis, Aeronautical and Automotive Engineering, Loughborough University: Loughborough, UK, 2013.

56. Passmore, M.; Spencer, A.; Wood, D.; Jowsey, L. The Application of Particle Image Velocimetry in Automotive Aerodynamics. SAE Technol. Pap. 2010, 2. [CrossRef]

57. Varney, M. Base Drag Reduction for Squareback Road Vehicles. Ph.D. Thesis, Loughborough University: Loughborough, UK, 2020.

58. Peichl, M.; Mack, S.; Indinger, T.; Decker, F. Numerical Investigation of the Flow Around a Generic Car Using Dynamic Mode Decomposition. In Proceedings of the Fluids Engineering Division Summer Meeting, Chicago, IL, USA, 3-7 August 2014; pp. 1-8.

Publisher's Note: MDPI stays neutral with regard to jurisdictional claims in published maps and institutional affiliations. 